\title{
What Makes Diets Political? Moral Foundations and the Left-Wing-Vegan Connection
}

\author{
Thomas Grünhage $^{1}$ (D) Martin Reuter ${ }^{1,2,3}$
}

Accepted: 16 December 2020 / Published online: 6 February 2021

(C) The Author(s) 2021

\begin{abstract}
Though meat-consumption is known to be a key factor in environmental damage, veganism and vegetarianism are still perceived to be left-wing-phenomena, ironically not penetrating to those who hold ideologies of conservation. Logical contradictions and historical counter-examples cast doubt on a substantive connection between political orientation and meat-eating. Instead, common psychological factors may predispose people toward both: left vs. right-wing political orientation and self-restrictive vs. omnivore eating preferences. Moral foundations have been shown to explain why even seemingly contradictory issue stances are brought forward in the context of the same ideological or political orientation. Here, we expand on these findings by showing the moral foundations to connect political orientation and vegan and vegetarian eating preferences as well as specific strategies of meat-eating justification in a large German sample. Specifically, the binding foundations authority and purity as well as avoidance tendencies are shown to differentially interact with meat-eating across the political spectrum with stronger effects for left-wing adherents and centrists than for the right-wing. Mediation analyses reveal that substantive parts of the association between political orientation and self-restriction in eating are attributable to differences in the moral makeup of left- and right-wing adherents. Connecting our results to prior work on the explanatory power of moral foundations for the political polarization of environmentalism, we discuss how our results may inform inter-ideologically appealing communications of reducing meat consumption, which is a worthwhile and necessary goal for mitigating climate change.
\end{abstract}

Keywords Moral foundations theory $\cdot$ Ideology $\cdot$ Veganism $\cdot$ Vegetarianism $\cdot$ Moral judgement

Supplementary Information The online version contains supplementary material available at (https://doi. org/10.1007/s11211-020-00361-w).

Extended author information available on the last page of the article 


\section{Introduction}

Ideological threads seem to not only connect political preferences (even when these seem to be logically incompatible), but they also extend to the realm of individual lifestyles (Allen \& Ng, 2003; Allen, Wilson, Ng, \& Dunne, 2000; Carney, Jost, Gosling, \& Potter, 2008; Dhont \& Hodson, 2014; Dhont, Hodson, \& Leite, 2016; Dhont, Hodson, Costello, \& MacInnis, 2014; Dietz, Frisch, Kalo, Stern, \& Guagnano, 1995; Hyers, 2006; Ruby, 2012). Here, eating preferences represent a fascinating example as these may not qualify as an ideological battlefield per se but nonetheless are of political relevance in times of climate change (McMichael, Powles, Butler, \& Uauy, 2007). Today, the connection between vegan or vegetarian preferences and the left-wing seems natural or logical to many: "Foie Gras" would not be our first guess when asked to guess the favorite dish of left-wing party leaders. In turn, when asked for an example of vegetarian politicians, people would presumably need several trials until they come up with Adolf Hitler. So, why do veg (etari)ans tend to cluster on the left side of the political spectrum? How, in turn, can the individual decision about what (not) to eat represent an ideological cleavage, making, for example, the right-wing populist "Alternative für Deutschland" (AfD) of North-Rhine Westphalia to submit parliamentary questions about the "militant vegan scene" (AfD, 2018), while vegan web-forums condemn right-wing antivegan, anti-immigrant, and anti-homosexual policy positions altogether (Gebauer, 2017)? Are conservatives inevitably bound to refuse vegan or vegetarian ideas to mitigate climate change?

Moral Foundations Theory (MFT; Haidt, 2007; see also Haidt, 2001) offers an answer to these questions: MFT is based on Haidt's, (2001) social intuitionist approach to moral judgment (SIM). Herein, Haidt criticized moral psychology's and philosophy's one-sided worship of reason. He differentiates between moral intuition and moral reasoning, based on Zajonc's, (1980) division of mental processes into those, which are fast, automatic, affective, and phylogenetically and ontogenetically old vs. cognitive processes, which are slow, evolutionary younger and developing later in ontogeny. According to Haidt (2001), moral judgment is based mainly on moral intuitions, which lead to affectively charged cognitions about other's characteristics or actions in terms of good or bad. Importantly, people are not consciously aware of the processes leading to these outcomes. By contrast, moral reasoning represents a less emotional, more controlled process. Information is processed consciously to reach a moral judgment. Haidt's (2001) model integrates both processes, instead of dismissing the former: Morally relevant situations trigger moral intuitions. Via the so-called intuitive judgment link, these trigger a moral judgment appearing in consciousness automatically and effortlessly. Conscious reasoning may take place thereafter or even stay absent completely. Regularly, it is heavily influenced by the initial intuitions. Accordingly, it often serves to justify those with post hoc explanations and reasons. On rare occasions, marked by weak intuitions and high processing capacity, the initial intuition may be overwritten by moral reasoning (so-called reasoned judgment link). A second rational link of the 
model is called private reflection. Thereby, predominantly by techniques of roletaking, a person may catalyze competing intuitions.

Importantly, Haidt's model is not confined to the individual level: Individual judgments directly contribute to social norms (the social persuasion link), and the affective component of people's post hoc generated reasons triggers affectively charged intuitions in others (social persuasion) instead of convincing them rationally, which is an empirically rare incidence. While traditional moral judgment models focus on private reflection and reasoned judgment, Haidt (2001) emphasizes the intuitive links more to account for phenomena as moral dumbfounding, i.e., the maintenance of a moral judgment without supporting reasons (Haidt, Bjorklund, \& Murphy, 2000). According to Haidt (2001), traditional theories cannot explain these, as they inevitably assume that people can give reasons for moral judgments when these are made. Of note, the standing of moral dumbfounding as evidence for intuitionist theories of moral judgment has been questioned repeatedly. Cushman, Young, and Hauser (2006) for example point out, that being unable to answer why a certain behavior is judged as morally wrong does not exclude that a-possibly very simplistic-principle guiding these judgments is accessible consciously. More specifically, Royzman, Kim, and Leeman (2015; also see Guglielmo 2018) question whether people are willing to accept the negation of any harm in typical dumbfounding stories, proposing that harm-based and normative reasons may still guide people's judgements instead of unconscious processes. However, rigorous research showed, that people can indeed be unaware of principles that actually guide their judgements (Cushman et al., 2006) and that moral dumbfounding phenomena can be elicited reliably (McHugh, McGann, Igou, \& Kinsella, 2017). Thus, it seems justified to state that moral dumbfounding still (though not uncontroversially) is perceived to hint to the involvement of intuitive processes in moral judgment as proposed by the SIM.

Notably, the SIM is not the only theory of moral judgment, emphasizing the role of intuitions or emotions. A synthesis of predominantly rational and predominantly emotional (or intuitive) accounts of moral judgment can be seen in the work of Joshua Greene. Greene (2007, 2015) proposes a dual-process theory of moral judgment, referring to impressive neuroscientific evidence. Best explained with reference to different versions of the famous trolley dilemma (Thomson, 1985), the authors assume that initial, emotional reactions associated with higher activity in regions of the frontostriatal pathway and the default mode network conflict with rational reasoning associated with higher activity in the frontoparietal control network. Thereby, a prevailing emotional response as elicited by the footbridgeversion of the trolley dilemma for example (where the decision of sacrificing one life to save five entails the physical act of pushing a man in the trolley's way) leads to deontological judgments (i.e., those referring to oughts and duties as "do not kill ") while in the "switch " version of the dilemma (where one only needs to flick a switch to let the trolley go the "kill one " way) the rational processes prevail, leading to utilitarian judgments (i.e., those based on calculating of costs and benefits). Building on the work of Haidt (2001) and Greene (2007, 2015), Crockett (2013) and Cushman (2013) explain the dissociation of deontological vs. utilitarian judgements as reflective of a more general dissociation of model-free vs. model- 
based learning systems. Model-free mechanisms assign values to actions directly, while model-based mechanisms assign values to outcomes, which are connected to actions only via internal models of causality.

For all these intuitionist or dual-process theories of moral judgment, the source and structure of the moral intuitions or emotions are of immense relevance, and MFT offers a theory about their evolutionary development and their fundamental nature.

MFT describes five psychological systems, entailing specific emotional reactions, which evolved as adaptions to specific evolutionary problems. Following a moderate nativist approach, Haidt and Joseph (2004) describe those as an innate preparedness to construe and respond to the social world in a particular way (i.e., connecting social evaluations with emotional and motivational reactions). Affective flashes evoked by specific patterns in the social world and stemming from these foundations form the basis of concepts as virtues and vices developed und uphold by individuals and-ultimately-societies. Cultures, however, differ in their use of the foundations and the relative extension of the universal, evolutionary caused "proper" domains of a given foundation to more or less broad "actual" domains (e.g., by extending a general revulsion of pathogens, rotten food, etc. to " dirty " and "impure" outgroups or behaviors; Haidt and Joseph 2004).

In particular, the five foundations are called Harm, Fairness, Loyalty, Authority, and Purity, each of which is shortly described in the following.

(1) Harm evolved as an adaption to the evolutionary challenge of protecting one's offspring. A special sensitivity for signs of suffering, triggering sympathetic reactions, developed and (to differing degrees) extended to unrelated individuals. Virtue concepts as care, compassion, and kindness, as well as vice concepts as cruelty and aggression, are based on the harm foundation.

(2) Fairness serves the evolutionary challenge of gaining benefits in interaction with others. It triggers emotional reactions as gracefulness, anger, and guilt and is the innate base of virtue vs. vice concepts as honesty, trustworthiness, or insincerity.

(3) As living and cooperating within groups offered evolutionary advantages, social emotions as trust, pride, and contempt evolved, the common basis of which is the Loyalty-foundation. Associated virtues and vices are, for example, loyalty, self-sacrifice, treason, and cowardice.

(4) In negotiating within-group hierarchies, which offer advantages in betweengroup competition, emotions as respect, anxiety, and awe are at play, which are based on the Authority foundation. Virtuous leaders act generously and wisely; vicious ones are despotic or exploitative. Respectively, good subordinates are respectful and obedient, not arrogant or insubordinate.

(5) Lastly, the Purity foundation's central element is the emotion of disgust, serving to adapt to evolutionary challenges posed by microbes and parasites. Disgust developed to be a social emotion, laying the foundation for virtues as restraint, chastity, and cleanliness and vices as lust and self-indulgence (Haidt \& Graham, 2007; Haidt \& Joseph, 2004; Graham et al., 2013). 
The last three foundations are referred to as binding foundations, because they support groups' cohesion, whereas harm and fairness are called individualizing foundations, emphasizing individual rights (Graham, Haidt, \& Nosek, 2009). The five-factor structure of moral concerns has been confirmed repeatedly (Davies, Sibley, and Liu, 2014; Graham, Haidt, \& Nosek, 2009), though MFT may be complemented with additional foundations (Haidt \& Joseph, 2011). Nonetheless, while MFT refers to evolutionary roots and thus implicitly claims intercultural generalizability, the Moral Foundations Questionnaire, as its most widespread and sufficiently validated measure, falls short of standards of scalar invariance, casting doubts on results based on direct cross-cultural comparisons of means (Davis et al., 2016; Iurino \& Saucier, 2020). Furthermore, alternative factorial structures show comparable or even superior fit-indices, which, however, should be evaluated in consideration of the author's explicit decision to prioritize content breath over reliability (Graham et al., 2011; Iurino \& Saucier, 2020).

Though not intended to be, MFT is seen primarily as a political, psychological theory (Alford, Smith, Martin, Hatemi, \& Hibbing , 2016; Graham et al., 2013), due to Haidt and Graham's (2007) finding of a higher endorsement of binding foundations among conservatives. In many subsequent studies, the pattern of liberals focusing primarily on the individualizing foundations and conservatives showing a more balanced pattern was confirmed (Dickinson, McLeod, Bloomfield, \& Allred, 2016; Barnett, Öz, \& Marsden, 2018; Graham et al., 2013). It proved to be stable across methods as direct self-reports, judgments, taboo-trade-offs, and textanalysis and was referred to as the moral foundation hypothesis (Davis et al., 2016; Graham et al., 2009). Furthermore, it was impressively related to ideological narratives and expanded beyond the conservative/liberal dichotomy by showing specific settings of moral foundations in other ideological groups, especially libertarians (Haidt, Graham, \& Joseph, 2009; Iyer, Koleva, Graham, Ditto, \& Haidt, 2012). However, Davis et al.,(2016) demonstrated weaker relationships between conservatism and binding foundations in black samples, advising caution when generalizing the moral foundation hypothesis cross-culturally. According to the theory, Graham et al.,(2012) showed that liberals implicitly react to group-based moral concerns, but do not explicitly endorse them. Additionally, respective differences in moral foundation endorsement (see Simpson 2017, for a discussion of the difference between activation and endorsement) have been associated with other, ideologically variable outcomes. Examples are behavior to mitigate climate change (Dickinson et al., 2016), punitiveness (Silver \& Silver, 2017), death qualification in sentencing decisions (Vaughan, Bell Holleran, \& Silver, 2019), homophobia (Barnett et al., 2018), public views on sexual offending (Harper \& Harris, 2017), attitudes against the poor (Low \& Wui, 2016), donating to charity (Nilsson, Erlandsson, \& Västfjäll, 2016) or phenomena as specific as attitudes toward needle exchange services for injecting drug users (Christie et al., 2019). Strengthening the conception of moral foundations as powerful predictors of political attitudes, Koleva et al., (2012) showed that the moral foundations are predictive for American's stances on prototypical culture-war-issues, for example, abortion or same-sex-marriage, thereby representing moral threads which connect 
even seemingly contradictory political positions, as concurrent support for capital punishment and pro-life-engagement in a conservative context.

Of note, being a popular and influential theory of political psychology, MFT did not remain uncriticized. Apart from critics questioning the multi-factorial model of MFT per se (Crone \& Laham, 2015; Schein \& Gray, 2015; but see Simpson, 2017), possible normative implications (Kugler, Jost, \& Noorbaloochi, 2014), or the causal order of the relationship between political orientation and moral foundations (Alford et al., 2016; but see Koleva et al., 2012; Yilmaz \& Saribay, 2017), the conceptualization of certain foundations, especially of purity, was criticized as one-sided, i.e., focusing too strongly on values as chastity or conceptions of sin (Frimer, Tell, \& Motyl, 2017; Suhler \& Churchland, 2011).

Both Koleva et al.'s., (2012) demonstration of the moral foundations' explanatory power regarding the connection of seemingly contradictory policy stances and Suhler \& Churchland's (2011) description of the purity foundation create an interesting frame for testing the moral foundations' explanatory power with regard to the left-wing-veg*n connection.

Contrary to what people may expect based on the fact that disgust of meat is a prominent motivational factor for many veg*ns (Ruby, 2012), it is plausible that purity-along with the other binding foundations-is by and large negatively associated with vegetarian, vegan and comparable self-restrictive (hereafter referred to as veg*n) lifestyles. Purity may negatively influence veg*n attitudes by bolstering meat-eating-justification strategies, as trying not to think about animal suffering, holding the view that significant differences between pets and livestock exist, or trying not to associate meat with living beings. Generally, a moral-foundations based account may allow for a deeper understanding of the ostensibly "logical "connection between a leftist political orientation and veg*n attitudes.

Why did we call the left-wing-veg*n connection "ostensibly" logical? While many see veg*n lifestyle and left-wing political orientation as a natural match today, a mere glance at history provides important counterexamples: The first modern law for the protection of animals was passed on November 24, 1933, in Nazi-Germany. Hitler, nowadays being one of world history's most prominent practitioners of vegetarianism alongside Pythagoras, Da Vinci, Benjamin Franklin, George Bernard Shaw, and Mahatma Gandhi, was awarded the gold medal of the Eichenberger foundation in Seattle and honorary certificates of New York's animal protection associations (Friedrich, 2018; Spencer, 1996). Of course, the personal preferences of political leaders should not be overinterpreted. However, since the example shows that even most extreme right-wing governments or tyrannies can actively engage in animal protection, doubts concerning a natural, logical, or content-based connection between veg*nism and the political left are certainly indicated. Of note, this is not to dispute systematic differences between the left- and the right-wing concerning the prevalence of veg*n lifestyles and associated attitudes and values, which have been reported extensively. Instead, we hypothesize that these differences are attributable in large parts to differences in psychological dispositions, namely the moral foundations, not to a coercive content-based overlap of veg*n and left-wing or anti-veg*n and right-wing ideologies. 
Veg*nism has been associated with ideological self-placements, policy stances, and prominent correlates and psychological foundations of ideology as Right-WingAuthoritarianism (RWA; Altemeyer, 1981) or Social Dominance Orientation (SDO; Pratto, Sidanius, Stallworth, \& Malle, 1994). Liberalism massively increases the odds of being vegetarian (White, Seymour, \& Frank, 1999), while conservatism predicts speciesism (Dhont et al., 2016). German veg*ns self-categorize rather on the left side of the political spectrum (Pfeiler \& Egloff, 2018). British veg*ns more likely favor redistribution of wealth and engage in charitable organizations and local politics (Gale, Deary, Batty, \& Schoon, 2007) and values as obedience, security, and order are negatively, equality and social justice positively associated with veg*nism (Dietz et al., 1995). Kalof, Dietz, Stern, \& Guagnano, (1999) reported similar findings with regard to altruistic vs. traditional values. Expectably, veg*ns care more for the ecological consequences of their food-choice (Hoek, Luning, Stafleu, \& De Graaf, 2004). Hamilton (2006) reports that veg*ns not only oppose foxhunting and other sports entailing the killing of animals, but also capital punishment and nuclear armament. Omnivores are more likely to endorse RWA and SDO (Allen et al., 2000), and people scoring high on measures of authoritarianism tend to be critical of environmental activism (Peterson, Doty, \& Winter, 1993). Hodson \& Earle, (2018) found that conservatism predicts lapsing back from veg*n diets to meat consumption. Speciesism is by and large associated with (extreme) right-wing phenomena as RWA, SDO, system justification, racism, sexism, and homophobia (Caviola, Everett, \& Faber, 2019). In addition, there is extensive literature on the negative association between veg*nism and masculinity (Rothgerber, 2013; Adams, 1990). Overall, veg*ns are perceived to be less masculine than omnivores, even by fellow veg*ns (Ruby \& Heine, 2011) —an association that even seems to expand to the subliminal realm (Rozin, Hormes, Faith, \& Wansink, 2012).

In making sense of cumulating results like these, Dhont and Hodson (2014) proposed that RWA and, predominantly, SDO, which represent the key-elements of conservatism (Jost, Glaser, Kruglanski, \& Sulloway, 2003), are associated with meat consumption via two paths: the perceived threat posed by veg*n ideologies to the dominant (meat-eating) ideology and the belief in human supremacy over animals. Furthermore, Dhont et al., (2014) proposed and demonstrated SDO to account for the association between speciesist and anti-outgroup attitudes, thereby explaining the seemingly stable relationship between veg*nism and political orientation (also see Hyers, 2006), thus offering a theory of common psychological associations being responsible for the left-wing-veg*n connection.

We suggest that a moral foundations framework may supplement these accounts in a valuable way: Due to its broader scope, it may even help explain historical examples as the adoption of animal-protectionism by the Nazi administration, who certainly propagated social dominance, though self-presenting as animal-lovers. Likewise, the differentiation of MFTs multiple factors may prove helpful in the analysis of (extreme) right-wing political messages associating animal welfare with group-based enmity by pointing to Islamic, Jewish, or otherwise outgroup-ascribed animal torture (as traditional forms of slaughtering, for example) to spread outgroup-derogative narratives (Haidt \& Joseph, 2004). Lastly, moral foundations, by definition, represent partially inherited, but culturally malleable dispositions. 
Also, the same foundation represents the base of various virtues and vices, which a society adopts. Thereby, for example, instead of disputing conservatives claims of human supremacy over animals (which would be based on the authority-dimension in an MFT-framework), the spread of veg*nism may be better served by emphasizing virtues, also associated with the respective foundation, for example, as generosity or other attributes of a good leader. Likewise, MFT can be consulted to generate a host of potentially very effective communication strategies (see discussion). In this regard, framing appeals to be consistent with binding moral foundations was repeatedly shown to increase environmentalist intentions and behavior in conservatives, as will be outlined in the discussion (Feinberg \& Willer, 2013; Kidwell, Farmer, \& Hardesty, 2013; Wolsko, Ariceaga, \& Seiden, 2016; also see Gromet, Kunreuther, \& Larrick, 2013; Kidwell et al., 2013 for possible negative consequences of inconsistent framing).

To sum up, we assumed that moral foundations would connect political orientation and veg*n attitudes and behaviors, potentially offering valuable insights for political communication.

Accordingly, we hypothesized that veg*ns differ from omnivores in their political orientation and in their moral makeup, i.e., their endorsement of the moral foundations. We expected meat-eating to be positively correlated with right-wingpolitical orientation and a stronger endorsement of binding as opposed to individualizing foundations. Moderation analyses were employed to gain insights on whether meat-eating is associated with the moral makeup differentially across the political spectrum, i.e., on how left-wing veg*ns (or those consuming less animal products) differ from left-wing omnivores (or those consuming more animal products) and how these groups differ within a right-wing context. Crucially, we predicted that differing endorsements of the moral foundations partially explain the association between political orientation and veg*nism. Additionally, we explored to what extent specific meat-eating justification strategies differ across the political camps and how these interact with moral foundations when meat-consumption is predicted by the political orientation. Lastly, we hypothesized that the moral foundations would be an at least equally powerful mediator of the association between political orientation and veg*nism as SDO.

\section{Material and Methods}

\section{Participants}

The sample consisted of $N=670$ participants. The mean age was 28.48 years $(\mathrm{SD}=11.05)$. Educational levels were fairly high: Asked for their highest educational achievement, 38.7\% stated a general qualification for university entrance (German "Abitur "), 45.5\% had graduated from university, $4.2 \%$ achieved the vocational baccalaureate ("Fachabitur"), $4.8 \%$ acquired the intermediate school-leaving certificate ("mittlere Reife") and $0.9 \%$ the basic school qualification ("Hauptschulabschluss"). 
Females $(73.4 \%)$ were overrepresented compared to males $(26.4 \%)$, and those self-describing as diverse $(0.1 \%)$. To enlarge our sample and avoid the restriction on undergraduates, we decided to computerize our study and make it accessible online. Participants were recruited via online and offline advertisements, predominantly via mailing-lists and diverse theme-oriented or local web-forums. Participants received no financial compensation. Only complete data sets were included in the analyses. Nevertheless, university students $(61.8 \%)$ were overrepresented. $30 \%$ were employed. The remaining $8.2 \%$ distributed across students, apprentices, trainees, retirees, homemakers, unemployed people, and those in military or civil service.

$65.1 \%$ indicated not to self-restrict in eating, 9.6\% were pescetarians (eating fish but no meat), $19 \%$ self-described as ovo-lacto-vegetarians (eating no meat and no fish but milk products or eggs; hereinafter referred to as vegetarians), and $6.4 \%$ categorized themselves as vegans (not eating fish, meat, milk products, and eggs). Regarding the political orientation, left-wing oriented participants were overrepresented: $69.3 \%$ reached a value below four on a seven-level left-right scale $(M=2.97 ; \mathrm{SD}=1.10)$.

\section{Questionnaires and Wahl-O-Mat}

\section{Moral Foundations Questionnaire}

For comparability with a multitude of studies examining moral foundations, we used the original Moral Foundations Questionnaire (MFQ; Graham et al., 2011) in its German translation (Jockel, Dogruel, Arendt, Stahl, \& Bowman, 2010). The MFQ consists of two subscales, which are called Relevance and Judgement. The relevance scale assesses explicit assumptions about what is morally relevant (When you decide whether something is right or wrong, to what extent are the following considerations relevant to your thinking?). Examples of the 15 items (three per foundation) of the relevance scale are "whether or not someone did something disgusting" (purity) or "whether or not someone was denied his or her rights" (fairness). Items are to be answered on a 6 point Likert-scale ("not at all relevant" to "extremely relevant"). The judgment scale also encompasses 15 items (three per foundation) to assess, which foundations are, in fact, relied on intuitively. Here, items take the form of short statements, which participants are asked to judge on a six-level Likert-scale (0: "strongly disagree" to 5: "strongly agree"). Exemplary items are "It is more important to be a team player than to express oneself" (loyalty) or "It can never be right to kill a human being" (harm). Within the subscales, items were presented in a randomized order. Two control items allow for controlling formal response biases. In the present sample, reliabilities in terms of internal consistencies for the five foundations (each combining relevance- and judgementscales of the MFQ) were: Care: $\alpha=0.67$; Fairness: $\alpha=0.68$; Loyalty: $\alpha=0.54$; Authority: $\alpha=0.70$; Purity: $\alpha=0.76$. To gain the Progress score, means of binding foundations were subtracted from the means of the individualizing foundations. The MFQ has been validated extensively (see Graham et al., 2011; Davies et al., 2014). In our sample, a factor- and principal component analysis with varimax rotation both yielded six-factor solutions. Harm- and fairness-items tended to cluster on one 
factor, loyalty, authority- and purity-items on another, while some foundation's items additionally loaded on separate, rather exclusive factors. This resembles results found by Graham et al., (2011). Given the concurrent increase of binding foundations on the political right, as postulated by the moral foundation hypothesis, such a pattern is not too surprising, especially in light of Graham et al.'s, (2011) explicitly stated prioritization of content-breath over internal consistency. The factor loadings can be found in the online appendix.

In addition to the MFQ, participants answered the Moral Foundation Vignettes (MFV; Clifford, Iyengar, Cabeza, \& Sinnott-Armstrong, 2015). Here, participants are asked to state the extent to which concrete behaviors described in short vignettes are morally wrong on a five-point scale. The MFV is described in detail in the online appendix. All analyses reported in the following were repeated using the MFV. Results are reported in the online appendix.

\section{Self-Placements}

Following common practice, we asked the participants for self-ratings of their political orientation. Specifically, we used four items, the first of which referred to "politics in general". On a subsequent page, participants were asked for selfplacements "with regard to social policies" and "with regard to economic policies". For these three items, a seven-point Likert-scale, ranging from "very conservative" to "very liberal" was used. We chose to use four instead of only one general item, to be able to detect misconceptions of the terms "liberal" and "conservative", which could be caused by the pervasiveness of terms as "neoliberalism" and-especially in Germany-by the self-description of the FDP as "the Liberals", both referring to the denial of regulations in the economic realm for the most part. These positions, paradoxically, should be coined "conservative" (Grünhage \& Reuter, 2020). Additionally, participants were asked to indicate their political orientation on a seven-point Likert-scale ranging from "left" to "right". Lastly, participants were asked to indicate which party they voted for in the last federal election in 2017 and which party they would vote for if the next federal election were held next Sunday (voting-intention; here, we explicitly asked for the second vote only, which in Germany is critical for the number of seats in the parliament). Since we observed that the left-right self-placement was predicted strongly by the others except for a somewhat weaker association with the economic item (see online appendix), which is probably due to the potential misunderstanding we anticipated, the left-right selfplacement served as our primary indicator of political orientation.

\section{Wahl-O-Mat 2017}

In addition to the self-placements, we used Wahl-O-Mat to gain an issue-based measure of political orientation. The "Wahl-O-Mat" (WoM) is a web-based VotingAdvice-Application offered by the federal agency for political education in Germany. Initially constructed in 2002, it is consistently updated prior to elections on the state, federal, or European levels. Originally intended to provide information for young people voting for the first time, it has been widely accepted in Germany 
and has been used more than 50 Million times in total prior to elections. The instrument nowadays consists of 38 statements, chosen and formulated by an invited council, which are answered by the German parties. The whole construction process is supervised by political scientists. The parties, as well as the participants, can rate their support for the statements by clicking "agree", "disagree", or "neutral". Also, participants can skip certain statements and indicate which statements are especially important to them. The answers to those items marked as important will be doubleweighted. The actual statements can be described as concrete policy-positions. For example, in the run-up to the federal election in 2017, participants could rate their support for statements as "In Germany, a general speed limit should be introduced" or "Video surveillance should be expanded in public space". We replicated the original WoM algorithm, which compares the answers of the participant and the several German parties, resulting in a percentual score of accordance. All parties currently represented in the German parliament were included: the Alternative für Deutschland (AfD), a party usually ascribed to right-wing-populism, the Freie Demokratische Partei (FDP), a party known for its economic liberalism, the Christlich-Demokratische/Christlich-Soziale-Union (Union), the traditional conservative party of Chancellor Angela Merkel, the Sozialdemokratische Partei Deutschlands (SPD), Germany's social democratic party, Bündnis 90 / Die Grünen, a green party explicitly pronouncing the need for protection of nature and Die Linke, a party confessing to the aim of democratic socialism (bpb, 2017). According to data from one of Germany's most renowned polling agencies, "Infratest dimap", based on a representative survey, the order of this list represents public ratings concerning the parties' location on a right-left continuum (Infratest dimap, 2015). So, we gained six scores of percentual accordance with each of the mentioned parties per participant. To create a concise WoM-score (WoM_com), we referred to the results of Infratest dimap (2015) and weighted the individual accordance-scores by the relative position the representative sample ascribed to them on a left-rightcontinuum before averaging them. As the accordance-scores with parties right-ofcenter were multiplied with a positive value that represents its perceived distance from the center and the accordance-scores with left-of-center parties were weighted by respective negative values, higher values in the resulting WoM_com variables represent more rightist attitudes. To avoid expectancy-effects and, especially, to avoid party-identification processes that could lead participants to answer the questions in line with what they think are the positions of their preferred party, we did not inform our participants that they were answering the WoM.

\section{Meat-Eating Justification Scale}

The Meat-eating Justification Scale (MEJ; Rothgerber, 2013); German translation by Markett, 2016) was used to assess strategies to justify the consumption of animal products. The instrument contains nine first-order subscales with three items each: Pro-meat attitude (e.g., "I enjoy eating meat too much to ever give it up."; $\alpha=0.82$ ), Denial (e.g., "Animals don't really suffer when being raised and killed for meat."; $\alpha=0.60$ ), Hierarchical Justification (e.g., "Humans are at the top of the food chain and meant to eat animals"; $\alpha=0.79$ ), Dichotomization (e.g., "To me, 
there is a real difference between animals we keep as pets and animals we eat as Food."; $\alpha=0.52$ ), Dissociation (e.g., "When I look at meat, I try hard not to connect it with an animal."; $\alpha=0.75$ ), Religious Justification (e.g., "God intended for us to eat animals."; $\alpha=0.87$ ), Avoidance ("I try not to think about what goes on in slaughterhouses."; $\alpha=0.71$ ), Health Justification (e.g., "We need the protein we can only get in meat for healthy development."; $\alpha=0.89$ ) and Human Fate Justification (e.g., "Our early ancestors ate meat, and we are supposed to, also."; $\alpha=0.72)$. Items are to be answered on a nine-point Likert-scale $(1=$ strongly disagree; 9 = strongly agree). Dissociation and avoidance are classified as indirect strategies $(\alpha=0.81)$, whereas all the others are referred to as direct strategies ( $\alpha=0.91$ ). Internal consistencies were calculated for the present sample. For the total scale, $\alpha=0.90$ was achieved. Direct vs. indirect strategies have been shown to be differentially endorsed by males vs. females. Also, endorsement of direct strategies has been associated with masculinity (Rothgerber, 2013).

\section{Self-Restriction in Eating}

Participants were directly asked whether they practiced any form of vegetarianism and categorized themselves as omnivores, ovo-lacto-vegetarians, pescetarians, or vegans (see Participants). Additionally, the following foods' average weekly consumption was assessed using an eight-point frequency scale ranging from "never" to "more than six times": Honey, fruit, pork, eggs, noodles, beef, fish/ seafood, vegetables, potatoes, and poultry. If participants had indicated to selfrestrict in eating, they could specify whether health-related considerations, disgust, ethical considerations, weight reduction, religious considerations, ecological reflections, or "other" aspects represent the main reason for doing so.

\section{Statistical Analyses}

To examine moral foundations' influence on $v^{*}{ }^{*} \mathrm{n}$ attitudes and behavior, first, self-identified groups of veg*ns vs. omnivores were compared with regard to MFQscores by analyses of covariance, controlling for age, gender, and educational status as potential confounds. Likewise, differences in ideology and meat-eating justification strategies were investigated. Second, partial correlations between ideological variables, moral foundations, and meat-eating justification strategies were computed, again controlling for the aforementioned demographics. The reported frequencies of meat and fish-consumption were factor-analyzed to gain a single measure for the actual consumption of animal products (CAP) using a principal component analysis. Moderation analyses were applied to investigate whether the associations between CAP or self-identifying as veg*n as predictors, and individual's endorsement of specific moral foundations or meat-eating justification strategies as criteria differ across the political spectrum. Simple slopes are presented for the categories centrist (mean of the political self-placement), left(-1SD) and right-leaning (+ 1SD). In addition, Johnson-Neyman significance regions were investigated. Subsequently, the CAP score was regressed on the selfplacement with the moral foundations as mediators to assess which part of the 


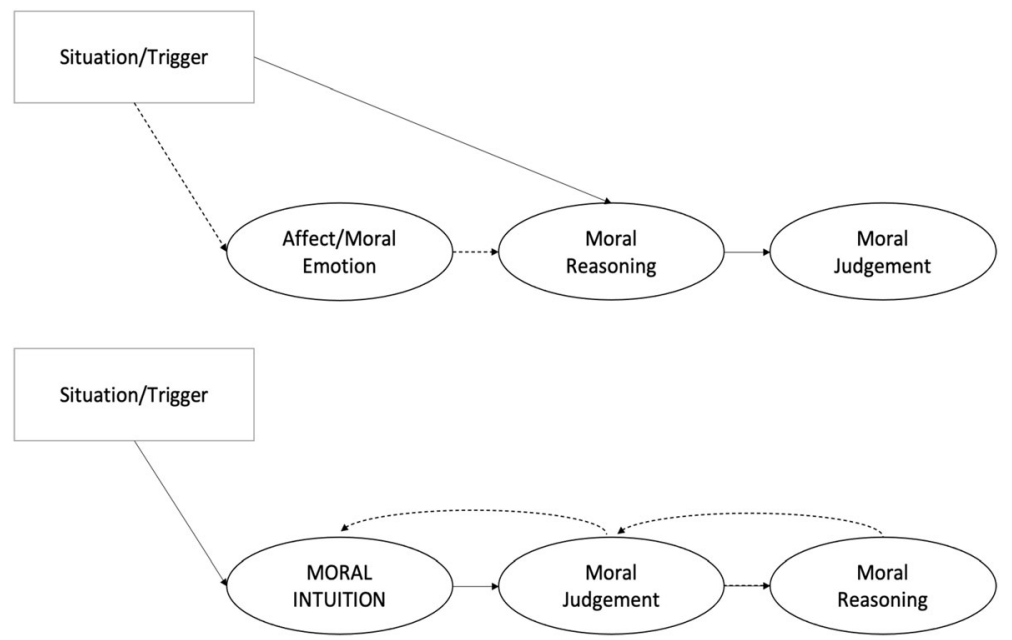

Fig. 1 Rational vs. social intuitionist models of moral judgement. Note Adopted from Haidt (2001). Simplified by the authors

association between ideology and veg*n behavior is attributable to differences in moral foundations. Likewise, meat-eating justification strategies were regressed on ideology as the predictor and moral foundations as mediators (cf. Fig. 2). Finally, dual, serial mediation models were analyzed, which entailed ideology as the predictor, CAP as the criterion and moral foundations as well as meat-eating justification strategies as mediators (see Fig. 3). These models allowed the first mediator (moral foundations) to influence the second (meat-eating justification strategies). Again, in all moderation and mediation models, age, gender, and educational status were included as covariates. Tolerances did not hint to critical multicollinearity in any model (all values $<0.50$ ). All analyses were computed with IBM Statistics vs.27 and the PROCESS macro for SPSS by Andrew Hayes (Hayes, 2017).

\section{Results}

For parsimony and due to massive intercorrelations among the political variables, we restrict the report of results to a single self-placement (left-right) and the concise WoM_com variable as measures of political orientation.

ANCOVAs contrasting self-identified veg*ns (including vegans, vegetarians and pescetarians) vs. omnivores showed stronger individualizing and weaker binding foundations (Harm: $\mathrm{F}_{(1,665)}=5.44, p=0.02, \eta_{\mathrm{p}}{ }^{2}=0.01$; Fairness: $\mathrm{F}_{(1,665)}=14.26$, 


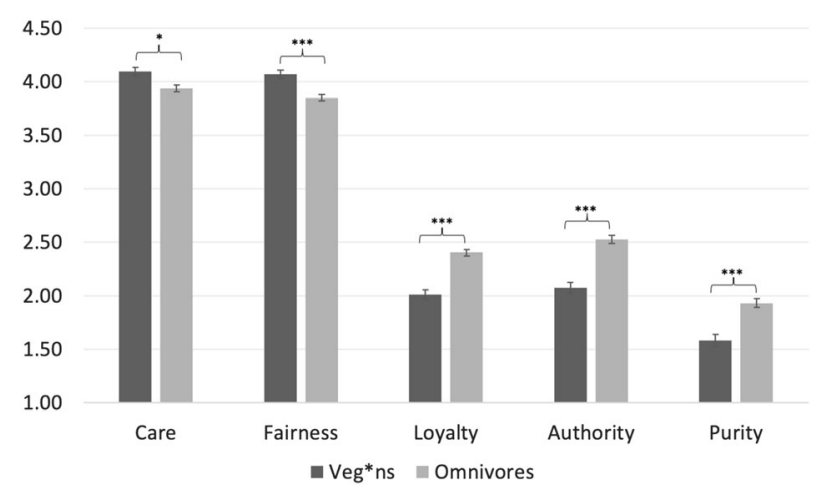

Fig. 2 Differences in moral foundations between veg*ns and omnivores. Note $* p \leq .05$, ** $\leq .01$, $* * * \leq .001$. Error bars depict the standard error of the mean

$p<0.001, \eta_{\mathrm{p}}^{2}=0.02$; Loyalty: $\mathrm{F}_{(1,665)}=46.01, p<0.001, \mathrm{n}_{\mathrm{p}}^{2}=0.07$; Authority: $\mathrm{F}_{(1,665)}=52.05, p<0.001, \eta_{\mathrm{p}}{ }^{2}=0.07$; Purity: $\mathrm{F}_{(1,665)}=24.51, p<0.001, \eta_{\mathrm{p}}{ }^{2-}$ $=0.04$; see Fig. 2) as well as rather left-wing political orientations among those who self-restrict in eating (self-placement: $\mathrm{F}_{(1,665)}=52.13, p<0.001, \eta_{\mathrm{p}}{ }^{2}=0.07$; WoM_com: $\mathrm{F}_{(1,665)}=70.02, p<0.001, \eta_{\mathrm{p}}{ }^{2}=0.10$; see Fig. 2).

See Table 1 for partial correlations between ideological variables, moral foundations, and meat-eating justification strategies, controlling for age, gender, and educational status.

Expectably, meat-eating justification strategies were less pronounced in veg*ns (Pro-Meat attitudes: $\mathrm{F}_{(1,665)}=352.52, p<0.001, \eta_{\mathrm{p}}{ }^{2}=0.35$; Denial: $\mathrm{F}_{(1,665)}=$ 110.84, $p<0.001 ; \quad \eta_{\mathrm{p}}{ }^{2}=0.14 ; \quad$ Hierarchical justification: $\mathrm{F}_{(1,665)}=200.13$, $p<0.001, \eta_{\mathrm{p}}{ }^{2}=0.23$; Dichotomization: $\mathrm{F}_{(1,665)}=92.24, p<0.001, \eta_{\mathrm{p}}{ }^{2}=0.12$; Dissociation: $\mathrm{F}_{(1,665)}=170.32, p<0.001, \quad \eta_{\mathrm{p}}{ }^{2}=0.20$; Religious justification: $\mathrm{F}_{(1,665)}=57.84, p<0.001, \eta_{\mathrm{p}}{ }^{2}=0.08$; Avoidance: $\mathrm{F}_{(1,665)}=7.28, p=0.007, \eta_{\mathrm{p}}{ }^{2-}$ $=0.01$; Health justification: $\mathrm{F}_{(1,665)}=311.13, p<0.001, \eta_{\mathrm{p}}{ }^{2}=0.32$; Human fate: $\mathrm{F}_{(1,665)}=197.86, \quad \mathrm{p}<0.001, \quad \eta_{\mathrm{p}}{ }^{2}=0.23 ; \quad$ Direct strategies: $\mathrm{F}_{(1,665)}=372.88$, $p<0.001, \eta_{\mathrm{p}}{ }^{2}=0.36$; Indirect Strategies: $\mathrm{F}_{(1,665)}=74.90, p<0.001, \eta_{\mathrm{p}}{ }^{2}=0.10$; Total: $\left.\mathrm{F}_{(1,665)}=418.15, p<0.001, \eta_{\mathrm{p}}{ }^{2}=0.39\right)$.

The four items measuring meat- and fish-consumption (pork, beef, poultry, fish/ seafood) on a frequency scale were factor-analyzed using a principal component analysis. The measure of sampling adequacy (KMO) reached 0.74 , indicating a "middling " to "meritorious " adequacy. As expected, applying the Kaiser criterion, only one factor was extracted (eigenvalue $=2.33$ ), explaining $58.35 \%$ of the overall variance. Factor-loadings were 0.75 (pork), 0.82 (beef), 0.68 (fish/seafood) and 0.81 (poultry). Given these values, factor-scores reasonably reflect the consumption of 
2.5

(A)

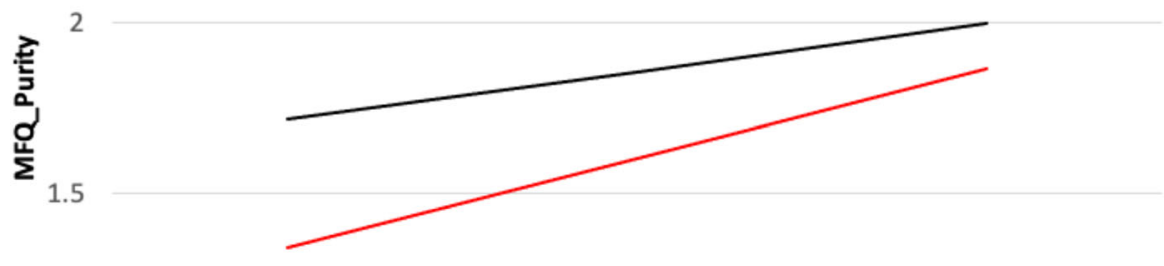

1

Low High

Consumption of Animal Products

(B)

3

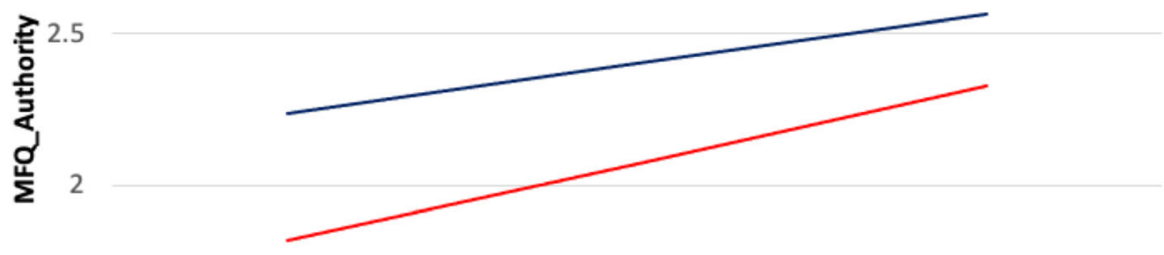

1.5

Average

High

Consumption of Animal Products

—Left-leaning —Centrist —Right-leaning

Fig. 3 Simple slopes: Meat-eating's association with the binding foundations purity (a) and authority (b) across the political spectrum

animal products (CAP). Table 1 shows bivariate partial correlations between ideological variables, MEJ-Subscales, moral foundations, and the CAP-Score, controlling for gender, age, and educational status. As expected, indicators of rightwing orientation were consistently positively associated with CAP. Naturally, the same was true for meat-eating justification strategies. Crucially, consistent with our hypotheses, binding foundations (including purity) were also positively associated with CAP.

Thus, up to this point, we have seen that veg*ns differ from omnivores with respect to their political orientation and their moral makeup and-in dimensional terms-that meat-eating is positively associated with a more right-wing political 


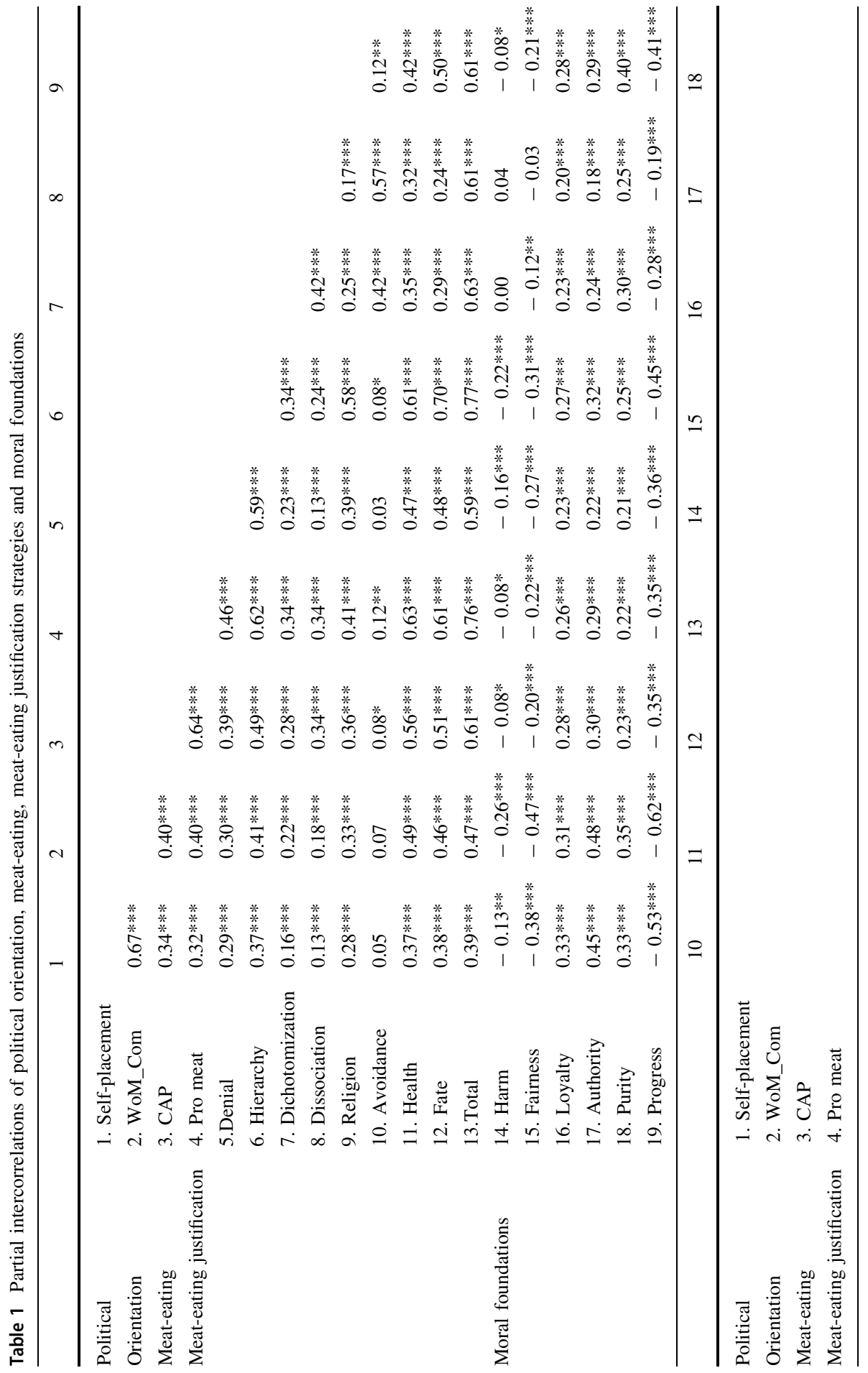




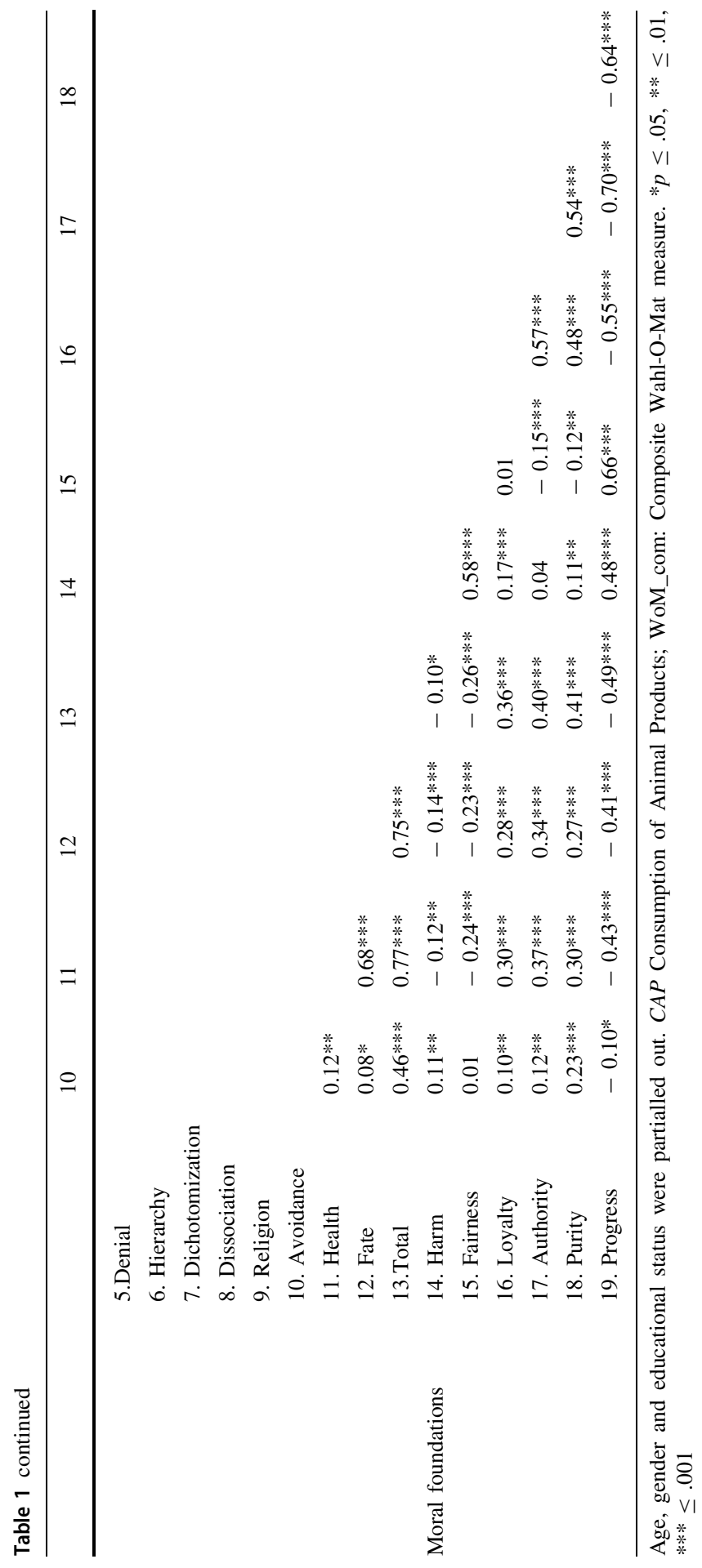


orientation and more pronounced binding as well as (slightly) less pronounced individualizing foundations. Additionally, a right-wing political orientation was shown to coincide with stronger endorsement of almost all meat-eating justification strategies. However, the question arises, whether political orientation and meateating interact in predicting moral foundations or meat-eating justification strategies, i.e., does meat-eating predict the endorsement of certain moral foundations or justification strategies differentially across left-and right-wing proponents or-schematically-how do left-wing omnivores differ from left-wing veg*ns and right-wing omnivores from right-wing veg*ns with regard to their moral makeup and their endorsement of specific justification strategies? Predicting harm-, fairness- and loyalty-scores by the CAP score and political orientation did not yield significant interaction effects (all ps $>0.080$ ). By contrast, significant interactions were found when predicting authority $\left.\left(\mathrm{F}_{(1,662)}\right)=11.00, p=0.001\right)$ and purity scores $\left.\left(\mathrm{F}_{(1,662)}\right)=15.15, p<0.001\right)$. CAP's effect on authority decreased across moderator values indicating left-leaning $(b=0.25, t=5.59, p<0.001)$, centrist $(b=0.16, t=5.24 . p<0.001)$ and right-leaning $(b=0.07, t=1.96, p=0.051)$ political orientations. This pattern was more pronounced for purity (left-leaning: $b=0.26, t=5.11, p<0.001$; centrist: $b=0.14, t=4.04, p<0.001$; right-leaning: $b=0.02, t=0.53, p=0.600$; see Fig. 3). Furthermore, Johnson-Neyman significance regions indicate that CAP's association with purity even becomes negative with stronger right-wing-orientation ( $\sim 2.4$ SDs). Replacing CAP by the dichotomous variable contrasting veg*ns vs. omnivores, led to similar results: The effect of veg*nism on authority and purity reached significance only at left-leaning ( $\mathrm{ps}<0.001)$ and centrist $(\mathrm{ps}<0.05)$ but not at right-leaning moderator levels ( $p s>0.41$ ). However, no reversal of the effect of veg*nism on purity with a more right-leaning orientation was found. Likewise, the justification strategies dichotomization, dissociation and avoidance are more strongly (or even exclusively) associated with meat-eating on the left and the center than on the right (see Table 2).

Mediation analyses (see Figs. 4 and 5) showed, that people's moral makeup, operationalized by the MFQ Progress score (i.e., the difference between the sum of means of the individualizing and the binding foundations; see methods), substantially mediates the associations between political orientation and meat-eating justification $\left(\mathrm{MEJ} ; \mathrm{F}_{(5,664)}=49.43, p<0.001, R^{2}=0.27\right)$ or actual consumption of animal products $\left(\mathrm{CAP} ; \mathrm{F}_{(5,663)}=35.38, p<0.001, R^{2}=0.21\right)$ respectively: For both dependent variables, substantial parts of the influence of political orientation are attributable to differences in moral foundations. The same was true when WoM_com replaced the self-placement as the measure of political orientation $\left(\mathrm{MEJ}: \mathrm{F}_{(5,664)}=55.99, p<0.001, R^{2}=0.30 ; \mathrm{CAP}: \mathrm{F}_{(5,663)}=39.79, p<0.001\right.$, $R^{2}=0.23$ ). See Tables 3 and 4 for detailed analyses on a subscale-level according to the conceptual models outlined in Fig. 6. Mediation effects of SDO-as expectedwere consistently smaller than those observed for the MFQ Progress score, i.e., 0.16 (vs. 0.21) for the prediction of $\operatorname{MEJ}\left(\mathrm{F}_{(5,664)}=38.93, p<0.001, R^{2}=0.23\right)$ and 0.08 (vs.12) for the prediction of $\operatorname{CAP}\left(\mathrm{F}_{(5,663)}=31.32, p<0.001, R^{2}=0.19\right)$ by the self-placement or 0.13 (vs 0.20 ) for the prediction of $\operatorname{MEJ}\left(\mathrm{F}_{(5,664)}=46.39\right.$, $p<0.001, \quad R^{2}=0.26$ ) and 0.04 (vs. 0.10 ) for the prediction of CAP $\left(\mathrm{F}_{(5,663)}=36.87, p<0.001, R^{2}=0.22\right)$ by WoM_com. 


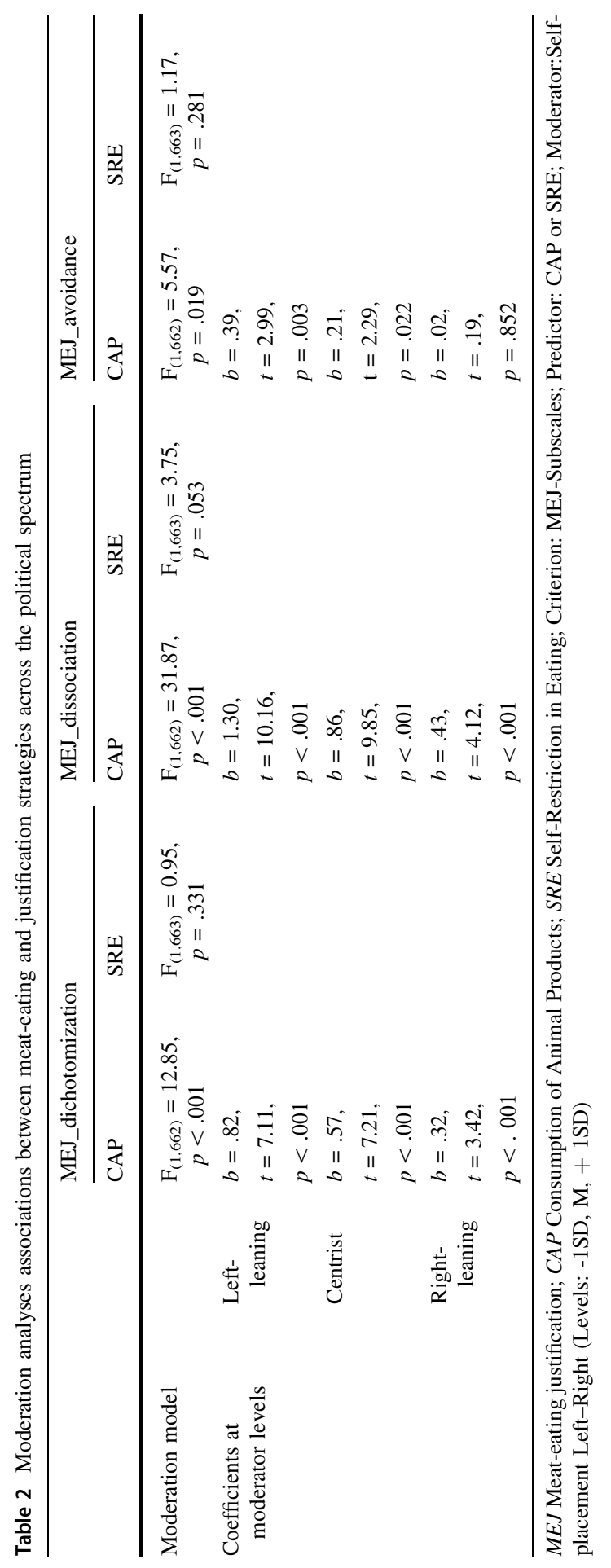



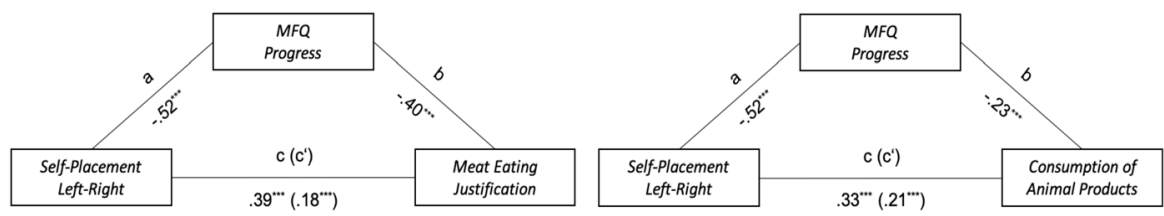

Fig. 4 Moral Foundations mediate the association between political orientation and meat-eating justification or consumption of animal products. Note c: total effect; c': direct effect; axb: indirect effect. $* p \leq .05, * * \leq .01, * * * \leq .001$
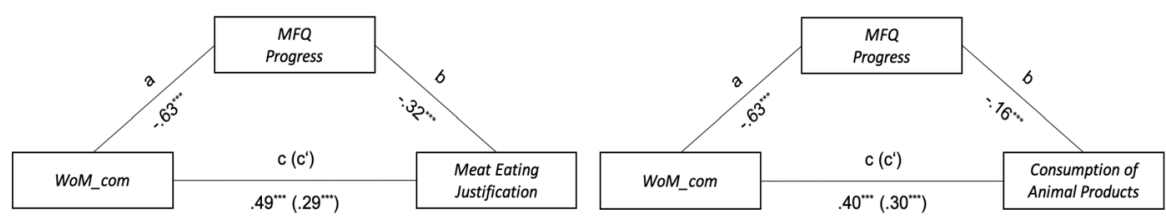

Fig. 5 Moral Foundations mediate the association between political orientation and meat-eating justification or consumption of animal products. Note: c: total effect; c': direct effect; axb: indirect effect. $* \mathrm{p} \leq .05, * * \leq .01, * * * \leq .001$

\section{Discussion}

By and large, our results shed light on the association between left-wing political orientation and veg*n attitudes and behaviors. To organize the discussion of our findings, one may distinguish between a "descriptive" and an "explanatory" part. On the "descriptive" level, in addition to replicating the expected association of political orientation and $\mathrm{veg}^{*}$ nism, we found consistent, positive relationships between the binding foundations and meat-eating justification strategies, significantly higher endorsement of individualizing and lower endorsement of binding foundations among veg*ns compared to omnivores, and positive associations between binding foundations (including purity) and the consumption of animal products. Moderation analyses revealed an interesting interplay of political orientation, moral foundations and meat-eating: For left-wingers and centrists, increases in meat-eating are associated with stronger endorsement of the purity foundation, while for right-wingers, who generally endorse purity more strongly, there is no further increase with meat-eating. By contrast, increasing meatconsumption may even coincide with lower purity scores on the (extreme) rightwing. The association between endorsement of the authority foundation and meateating also is stronger on the left, but remains (marginally) significantly positive across the spectrum. Likewise, the justification strategies of dichotomization, dissociation and avoidance were shown to be associated with increases in meateating more strongly (or, in the case of avoidance, exclusively) on the left and the center than on the right. Accordingly, our results hint to a pattern of left-wing and centrist omnivores differing from left-wing and centrist veg*ns in the endorsement of the purity and the authority foundation while - among right-wing adherents-no such pattern is found. 


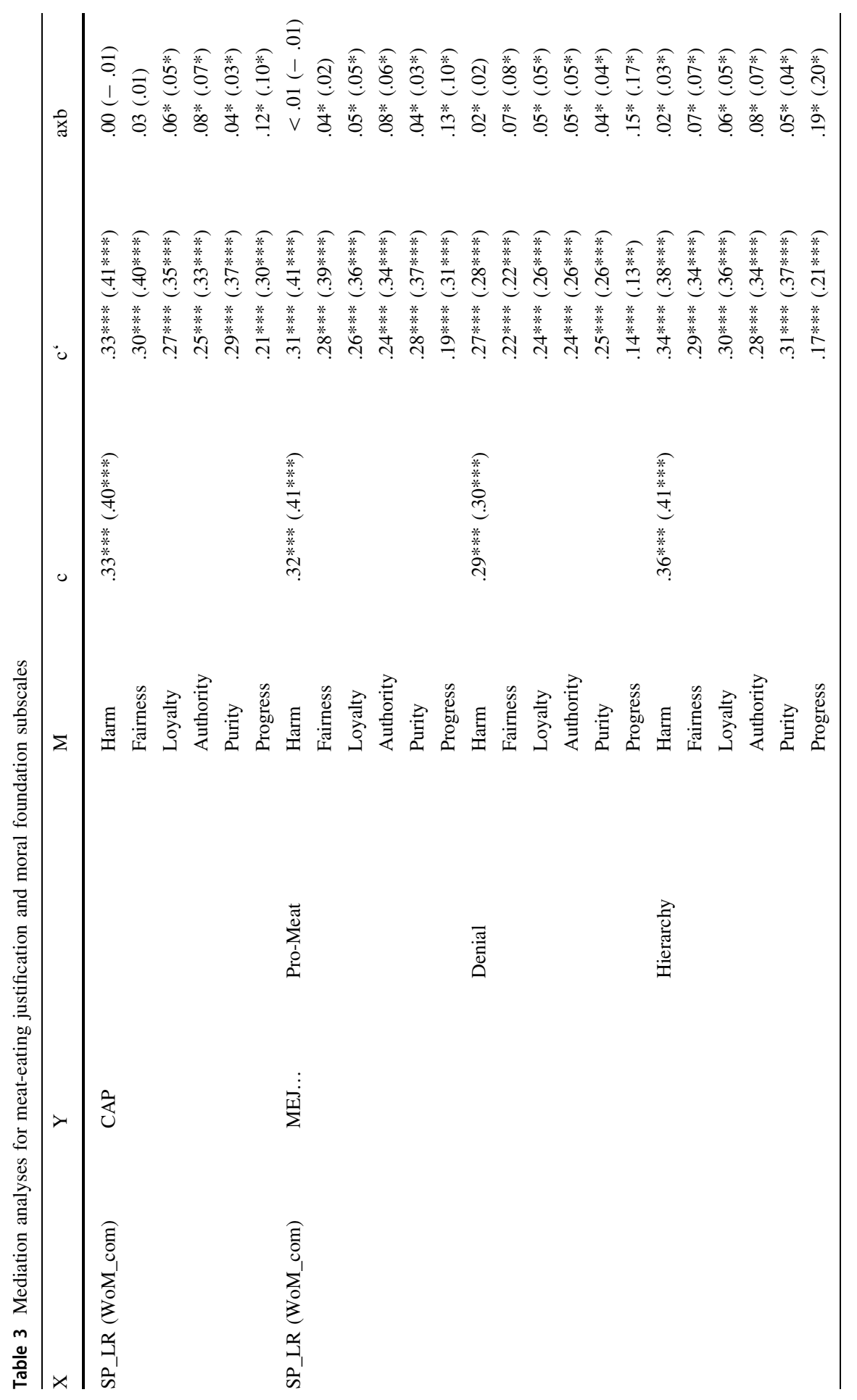




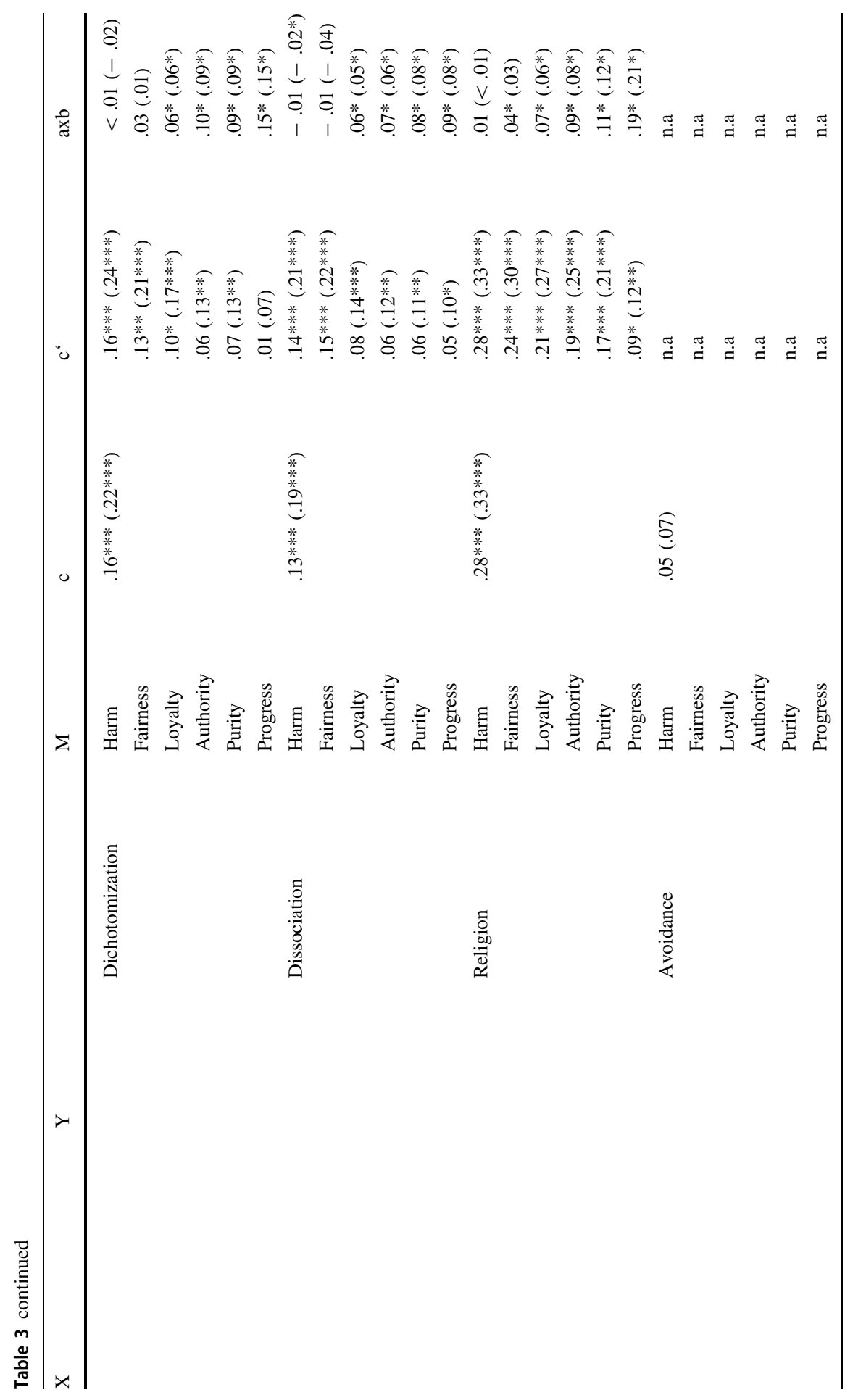




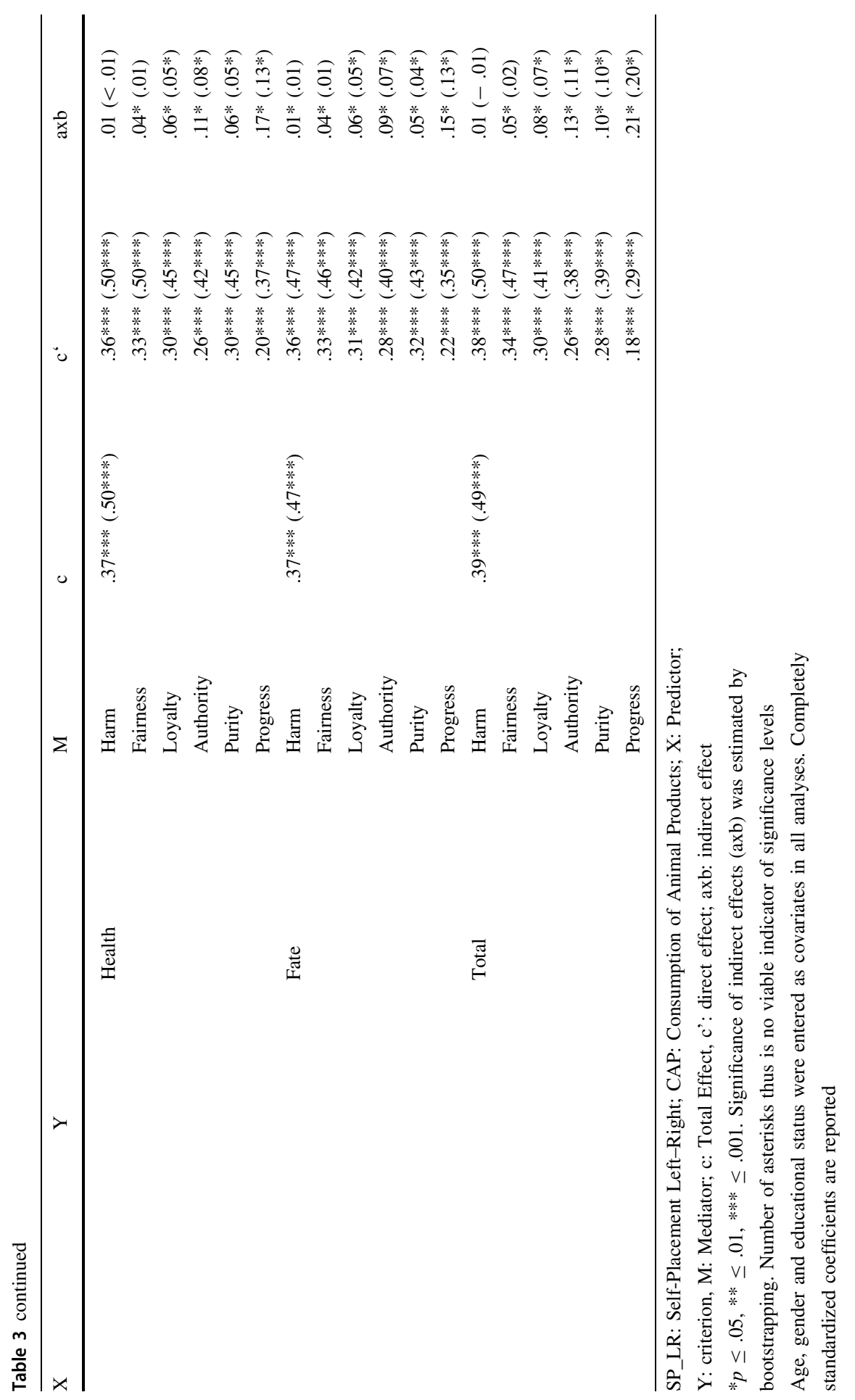




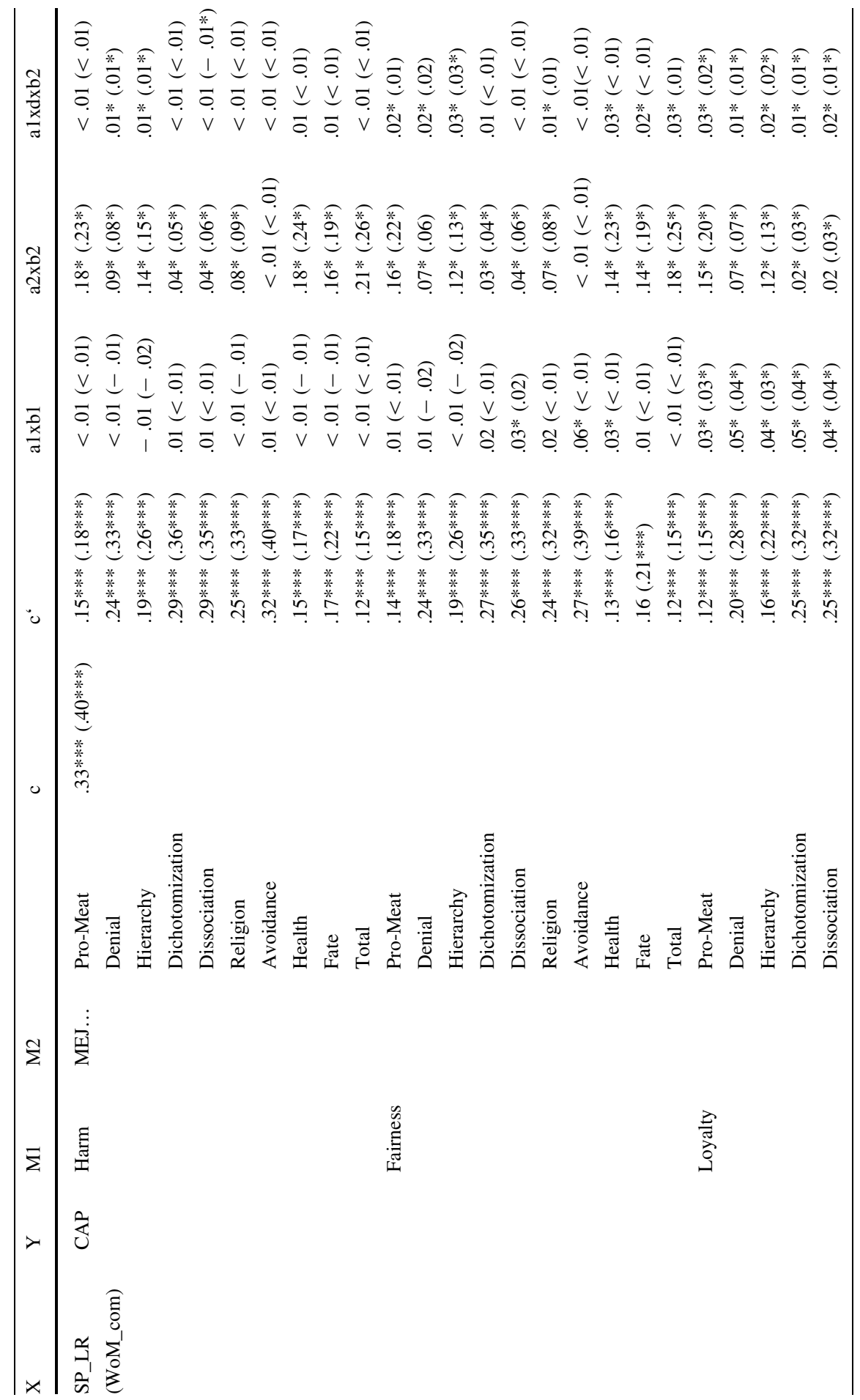




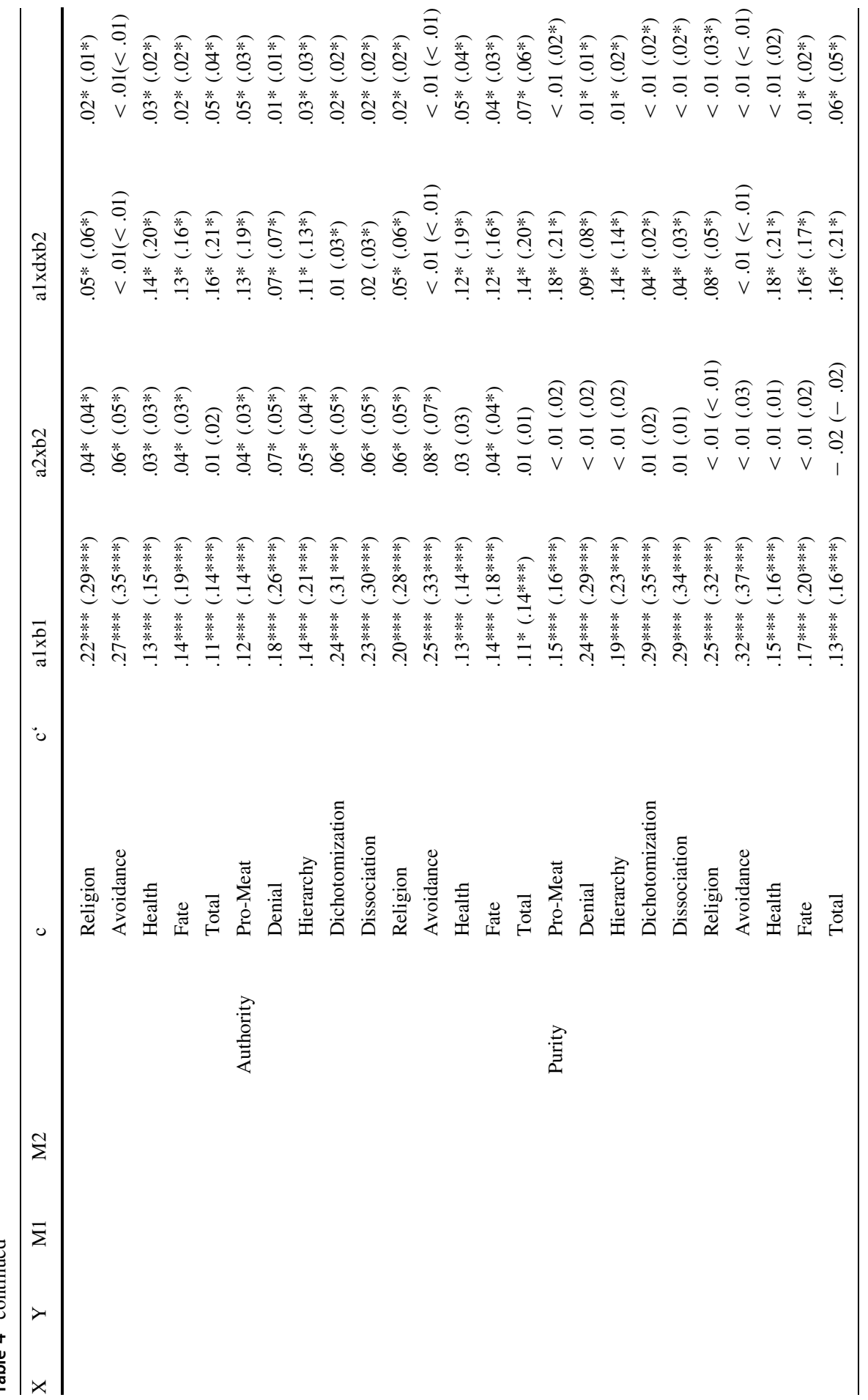




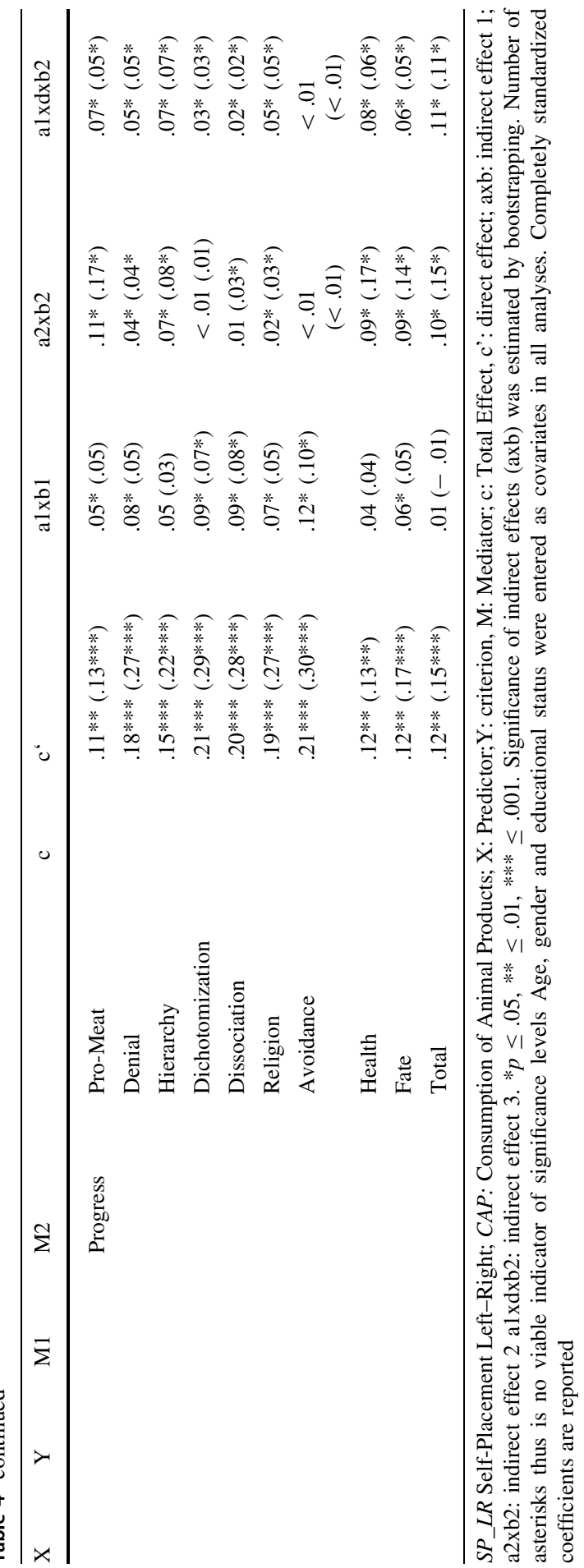




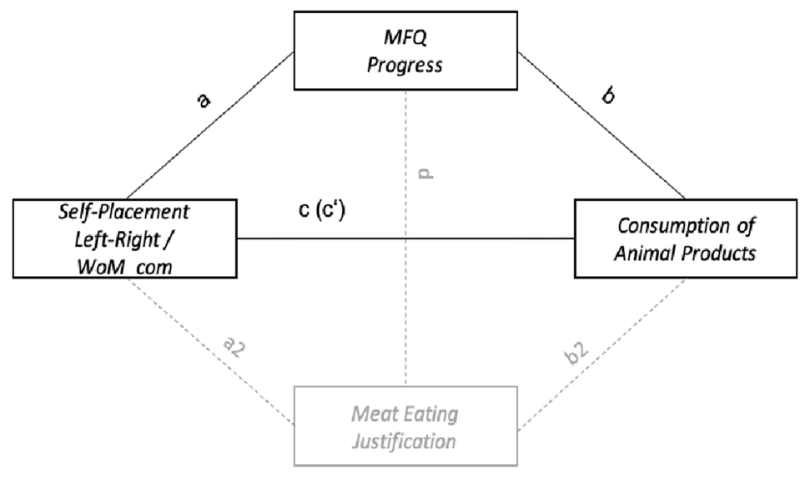

Fig. 6 Dual serial mediation model: Moral foundations and meat-eating justification strategies mediate the association between political orientation and consumption of animal products. Note: c: total effect; c': direct effect; axb: indirect effect1; a2xb2: indirect effect 2; axdxb2: indirect effect 3

On the "explanatory" level, mediation analyses revealed that a substantial part of the association between political orientation and veg*n outcomes is attributable to differences in moral foundations: We observed stronger endorsements of the binding foundations on the political right. Those binding-foundations, in turn, predict the adoption of meat-eating justification strategies as well as actual consumption of animal products. Of the binding foundations, purity is of particular interest (cf. Koleva et al., 2012). Our data show that purity counterintuitively acts against veg*n inclinations by positively influencing meat-eating justification strategies (also see Ruby, 2012).

Taken together, we conclude that the differential moral makeup of right- and leftwing adherents allows for a better understanding of the association between political orientation and veg*nism.

Associations between political orientation and veg*n attitudes or lifestyles have been shown before and sensibly traced back to common psychological dispositions, most prominently Social Dominance Orientation (Dhont et al., 2014, 2016; Hyers, 2006). Unlike these studies, here, we shed some light on the complex interplay between dispositional moral foundations, specific strategies of meat-eating justification, and outcome variables as self-identification as veg*n and actual consumption of animal products. In our opinion, using the moral foundations framework offers some advantages above and beyond identifying common psychological dispositions as SDO for right-wing orientations and meat-eating: Most relevantly, the social intuitionist model (Haidt, 2001), with its several links, identifies several paths of persuasion and ascribes rough probabilities of success to them. These may be used beneficially in progressive parties' strive to convince society to take measures necessary to mitigate climate change, first and foremost making veg*n diets more prevalent. Though scientifically valuable without a doubt, merely acknowledging that SDO mediates the association between right-wing and antiveg*n attitudes and values may lead to moral condemnation of right-wing meataficionados, which may well turn out to be counterproductive and offer ideological ammunition to right-wing populists. Differences in moral foundations, by contrast, 
can be communicated and used way more appreciatively. They offer a conceptual frame to prepare targeted arguments: For example, the pattern of the purity foundation's associations with meat-eating justification and actual meat consumption raises questions about the usefulness of shocking pictures and film recordings (of slaughterhouses, for example) to persuade conservatives of reducing their meatconsumption. Indeed, the results of our moderation analyses suggest, that these might rather affect fellow left-wingers as those-with increasing meat-consumption-tend to endorse the purity foundation more strongly. Among right-wingers, by contrast, growing consumption is not associated with a further increase in purity; our results even hint to the possibility that among strong right-wing-adherents, purity rather decreases with growing meat-consumption. With regard to justification strategies, the association of avoidance and meat-eating is equally confined to the left-wing and the political center. Hence, communication strategies as those outlined-aimed at evoking disgust and overcoming avoidance tendencies-may seem convincing to left-wingers but prove ineffective in persuading adherents of the opposite camp.

In line with previous work, the authority foundation (often also called "hierarchy") proved to be highly predictive of meat-eating and justification strategies. However, compared to SDO, which is often used as a measure of acceptance of inequality (Grünhage \& Reuter , 2020), authority in MFT is a broader construct: The virtues and vices associated with this dimension do not only encompass respect and obedience vs. insubordination and arrogance, but associated virtues also are characteristics of a good leader while despotism and exploitation (of subordinates) have been listed as vices which evolved out of this foundation (Haidt \& Graham, 2007; Haidt \& Joseph, 2004). Accordingly, it may be fruitful not to wait for conservatives to develop empathy with suffering animals, but, instead, offer them respect and appreciation for their generosity when they end or reduce meateating. In similar ways-given that moral foundations are seen as relatively stable psychological dispositions (see Haidt et al., 2009)-it may generally be worthwhile to search for "points of attack" within the conceptual space of a given, highly endorsed foundation before inducing conflict between these spaces. In line with the cognitive dissonance approach to meat-eating vs. veg*nism, Allen and Baines (2002) found that people informed about the link between meat-eating and social dominance orientation, reduced meat-eating and developed more negative attitudes toward meat. However, this effect was confined to those who did not endorse hierarchy and dominance values themselves. Thus, participants presumably tried to align their actions to their beliefs (Ruby, 2012). Likewise, Ruby (2012) reports evidence showing that the degree of negativity in omnivore's characterizations of vegetarians was predicted by the perceived moral depreciation of omnivores by vegetarians. Thus, a favorable view of conservative morality and a targeted search for points of contact within (and in terms of) the moral spheres of conservatives - as offered by MFT-may well serve veg*n agendas better than emphases of moral superiority.

These proposals for future studies and-ultimately-for effective social communication should not be seen as overly ambitious or speculative. There is a rich literature on how framing aimed at making appeals consistent with individual 
configurations of the moral foundations (or with related psychological dispositions) influences environmentalist intentions and even concrete behavior. Although environmentalism and veg*nism represent separate constructs as evidenced, for example, by the complex pattern of motivations reported by veg*ns, there certainly is some overlap (Ruby 2012). Furthermore, from a societal or functional perspective, the reduction of meat-consumption is a necessary and major part of environmental protection (McMichael et al., 2007). Just as veg*nism, environmentalism clearly is politically polarized (Dunlap, Xiao, \& McCright, 2001; Feygina, Jost, \& Goldsmith, 2010; McCright \& Dunlap, 2011). Feinberg \& Willer, (2013) demonstrated that this polarization is-in part-due to the moralization of environmental issues. Specifically, they showed that the environmental discourse is dominated by moral arguments based on the harm- and fairness-foundations, which are more compelling to liberals. However, when environmental messages were framed to resonate with the purity foundation, conservative's pro-environmental attitudes increased, eliminating differences between the political camps. Likewise, Wolsko et al., (2016) demonstrated that moral framing moderates the effects of political orientation on climate change attitudes, conservation intentions, and donations to an environmental organization. Again, while liberals did not differ across framing conditions, conservatives confronted with appeals resonating with binding foundations showed more positive environmental intentions, attitudes, and behavior than conservatives confronted with an appeal focusing on individualizing values or a control appeal. In contrast to the aforementioned studies, Kidwell et al., (2013) even showed symmetric crossover-interactions of political orientation and framing condition, i.e., individualizing frames increased environmental-friendly intentions and behavior in liberals, binding frames in conservatives. This discrepancy may be traced back to the specificity of the dependent variables examined here, which were concrete recycling intentions and actual recycling behavior. Outside of an explicit moral foundations framework, Feygina, Jost, and Goldsmith, (2010), building on system justification theory, demonstrated that the manipulation of two sentences framing pro-environmental change as patriotic and protecting the status quo is sufficient to eliminate differences between liberals in conservatives in pro-environmental intentions and actions.

These studies are promising and suggest that a moral foundation informed communication of the personal and societal advantages of veg*n lifestyles may well reduce actual meat-consumption. Of note, the divergent operationalizations of "environmentalism" in the studies described above seemingly led to interaction effects varying in strength. Thus, there is reason to expect that framing effects on the reduction of meat consumption may be even larger, because veg*nism-though undoubtedly complex-at least on the action level represents a relatively uniform construct, which is easier to grasp than the complex construct of environmentalism.

Of course, future research could and should be expanded beyond the boundaries of Moral Foundations Theory: Given that associations between meat-eating and perceptions of masculinity have been shown consistently, it may be overly ambitious to train down masculine habits and a general appreciation of masculinity in society to foster veg*nism. Instead, it may make sense to emphasize effects like those found by Havlicek and Lenochova (2006), who showed that body odors of 
males after a veg*n period are rated as significantly more attractive and pleasant by female raters and not as less masculine. This way, again, within the conceptual frame of masculinity-related values (encompassing being attractive to the opposite sex), the attractiveness of veg*n options could be fostered. The same presumably holds for other pressing issues in the context of climate change and beyond. Another promising path for future research would be to focus on the differential factors motivating people to become veg*n: The present results may well be differentiated further by taking distinctions as health-oriented vs. ethically motivated (e.g., Ruby, 2012) into account.

Summing up, our data showed systematic relationships between moral foundations, political orientation, meat-eating, and meat-eating justification strategies: Moral Foundations seem to represent a psychological factor predisposing for both right- vs. left-wing political orientation and meat-eating vs. veg*nism. Thereby, moral foundations partially explain the ostensibly "logical" but-at second glance-complex association of both. Additionally, our data showed that moral foundations and meat-eating justification strategies differentially interact with meateating across political camps. Hence, Moral Foundations Theory promises valuable advice to veg*n campaigns on how to frame their messages in order to reach liberals and conservatives alike.

Author Contributions TG contributed the data basis, statistical analysis and writing of the manuscript; MR supervised all steps and edited the manuscript.

Funding Open Access funding enabled and organized by Projekt DEAL. The authors received no financial support for the research, authorship and/or publication of this article.

Data Availability The data set (SPSS) is available here: https://doi.org/10.7910/DVN/DNU0VA.

Code Availability SPSS Syntax Code is available here: https://doi.org/10.7910/DVN/DNU0VA.

\section{Compliance with Ethical Standards}

Conflicts of interest The authors declare that they have no conflict of interest.

Open Access This article is licensed under a Creative Commons Attribution 4.0 International License, which permits use, sharing, adaptation, distribution and reproduction in any medium or format, as long as you give appropriate credit to the original author(s) and the source, provide a link to the Creative Commons licence, and indicate if changes were made. The images or other third party material in this article are included in the article's Creative Commons licence, unless indicated otherwise in a credit line to the material. If material is not included in the article's Creative Commons licence and your intended use is not permitted by statutory regulation or exceeds the permitted use, you will need to obtain permission directly from the copyright holder. To view a copy of this licence, visit http:// creativecommons.org/licenses/by/4.0/. 


\section{References}

Adams, C. J. (1990). The Sexual Politics of Meat: A Feminist-Vegetarian Critical Theory. New York: Continuum.

AfD. (2018). Militante Veganer - AfD Fraktion NRW. Retrieved May 12, 2020, from https://afd-fraktion. nrw/2018/08/02/militante-veganer/

Alford, J. R., Smith, K. B., Martin, N. G., Hatemi, P. K., \& Hibbing, J. R. (2016). Intuitive ethics and political orientations: Testing moral foundations as a theory of political ideology. American Journal of Political Science, 61(2), 424-437. https://doi.org/10.1111/ajps.12255.

Allen, M. W., \& Baines, S. (2002). Manipulating the symbolic meaning of meat to encourage greater acceptance of fruits and vegetables and less proclivity for red and white meat. Appetite, 38(2), 118-130. https://doi.org/10.1006/appe.2001.0474.

Allen, M. W., \& Ng, S. H. (2003). Human values, utilitarian benefits and identification: The case of meat. European Journal of Social Psychology, 33(1), 37-56. https://doi.org/10.1002/ejsp.128.

Allen, M. W., Wilson, M., Ng, S. H., \& Dunne, M. (2000). Values and beliefs of vegetarians and omnivores. Journal of Social Psychology, 140(4), 405-422. https://doi.org/10.1080/ 00224540009600481 .

Altemeyer, B. (1981). Right-Wing Authoritarianism. Manitoba: University Press.

Barnett, M. D., Öz, H. C. M., \& Marsden, A. D. (2018). Economic and social political ideology and homophobia: the mediating role of binding and individualizing moral foundations. Archives of Sexual Behavior, 47(4), 1183-1194. https://doi.org/10.1007/s10508-017-0989-2.

bpb. (2017). Wahl-O-Mat zur Bundestagswahl 2017. Retrieved May 5, 2020, from https://www.wahl-omat.de/bundestagswahl2017/main_app.php

Carney, D. R., Jost, J. T., Gosling, S. D., \& Potter, J. (2008). The secret lives of liberals and conservatives: Personality profiles, interaction styles, and the things they leave behind. Political Psychology, 29(6), 807-840. https://doi.org/10.1111/j.1467-9221.2008.00668.x.

Caviola, L., Everett, J. A. C., \& Faber, N. S. (2019). The moral standing of animals: Towards a psychology of speciesism. Journal of Personality and Social Psychology, 116(6), 1011-1029. https://doi.org/10.1037/pspp0000182.

Christie, N. C., Hsu, E., Iskiwitch, C., Iyer, R., Graham, J., Schwartz, B., \& Monterosso, J. R. (2019). The moral foundations of needle exchange attitudes. Social Cognition, 37(3), 229-246. https://doi.org/ 10.1521/soco.2019.37.3.229.

Clifford, S., Iyengar, V., Cabeza, R., \& Sinnott-Armstrong, W. (2015). Moral foundations vignettes: a standardized stimulus database of scenarios based on moral foundations theory. Behavior Research Methods, 47(4), 1178-1198. https://doi.org/10.3758/s13428-014-0551-2.

Crockett, M. J. (2013). Models of morality. Trends in Cognitive Sciences, 17(8), 363-366.

Crone, D. L., \& Laham, S. M. (2015). Multiple moral foundations predict responses to sacrificial dilemmas. Personality and Individual Differences, 85, 60-65. https://doi.org/10.1016/j.paid.2015. 04.041 .

Cushman, F. (2013). Action, outcome, and value: A dual-system framework for morality. Personality and Social Psychology Review, 17(3), 273-292.

Cushman, F., Young, L., \& Hauser, M. (2006). The role of conscious reasoning and intuition in moral judgment: Testing three principles of harm. Psychological Science, 17(12), 1082-1089. https://doi. org/10.1111/j.1467-9280.2006.01834.x.

Davies, C. L., Sibley, C. G., \& Liu, J. H. (2014). Confirmatory factor analysis of the moral foundations questionnaire. Social Psychology, 45, 431-436.

Davis, D. E., Rice, K., Van Tongeren, D. R., Hook, J. N., DeBlaere, C., Worthington, E. L., \& Choe, E. (2016). The moral foundations hypothesis does not replicate well in black samples. Journal of Personality and Social Psychology, 110(4), e23-e30. https://doi.org/10.1037/pspp0000056.

Dhont, K., \& Hodson, G. (2014). Why do right-wing adherents engage in more animal exploitation and meat consumption? Personality and Individual Differences, 64, 12-17.

Dhont, K., Hodson, G., Costello, K., \& MacInnis, C. C. (2014). Social dominance orientation connects prejudicial human-human and human- animal relations kristof. Personality and Individual Differences, 61, 51-108.

Dhont, K., Hodson, G., \& Leite, A. C. (2016). Common ideological roots of speciesism and generalized ethnic prejudice: The social dominance human-animal relations model (SD-HARM). European Journal of Personality, 30(6), 507-522. https://doi.org/10.1002/per.2069. 
Dickinson, J. L., McLeod, P., Bloomfield, R., \& Allred, S. (2016). Which moral foundations predict willingness to make lifestyle changes to avert climate change in the USA? PLoS ONE. https://doi. org/10.1371/journal.pone.0163852.

Dietz, T., Frisch, A. S., Kalo, L., Stern, P. C., \& Guagnano, G. A. (1995). Values and vegetarianism: An exploratory analysis. Rural Sociology, 60(3), 533-542.

Dunlap, R. E., Xiao, C., \& McCright, A. M. (2001). Politics and environment in America: Partisan and ideological cleavages in public support for environmentalism. Environmental Politics, 10(4), $23-48$. https://doi.org/10.1080/714000580.

Dunlap, R. E., \& Gale, R. P. (1974). Party membership and environmental politics: A legislative roll-call analysis. Social Science Quarterly, 50, 670-690.

Entman, R. M. (1993). Framing: Toward clarification of a fractured paradigm. Journal of Communication, 43(4), 51-58.

Feinberg, M., \& Willer, R. (2013). The moral roots of environmental attitudes. Psychological Science, 24(1), 56-62. https://doi.org/10.1177/0956797612449177.

Feygina, I., Jost, J. T., \& Goldsmith, R. E. (2010). System justification, the denial of global warming, and the possibility of "system-sanctioned change." Personality and Social Psychology Bulletin, 36(3), 326-338. https://doi.org/10.1177/0146167209351435.

Friedrich, C. (2018). Reichs-Tierschutzgesetz. Köln: Westdeutscher Rundfunk.

Frimer, J. A., Tell, C. E., \& Motyl, M. (2017). Sacralizing liberals and fair-minded conservatives: ideological symmetry in the moral motives in the culture war. Analyses of Social Issues and Public Policy, 17(1), 33-59. https://doi.org/10.1111/asap.12127.

Gale, C. R., Deary, I. J., Batty, G. D., \& Schoon, I. (2007). IQ in childhood and vegetarianism in adulthood: 1970 British cohort study. British Medical Journal, 334(7587), 245-248. https://doi.org/ 10.1136/bmj.39030.675069.55.

Gebauer. (2017). AFD sagt veganer Ernährung den Kampf an I vegan.eu I Dein veganes Infoportal. Retrieved May 12, 2020, from https://www.vegan.eu/afd-gegen-vegan/

Graham, J., Englander, Z., Morris, J. P., Hawkins, C. B., Haidt, J., \& Nosek, B. A. (2012). Warning bell: Liberals implicitly respond to group morality before rejecting it explicitly. SSRN Electronic Journal. https://doi.org/10.2139/ssrn.2071499.

Graham, J., Haidt, J., Koleva, S., Motyl, M., Iyer, R., Wojcik, S. P., \& Ditto, P. H. (2013). Moral foundations theory: The pragmatic validity of moral pluralism. Advances in Experimental Social Psychology. https://doi.org/10.1016/B978-0-12-407236-7.00002-4.

Graham, J., Haidt, J., \& Nosek, B. A. (2009). Liberals and conservatives rely on different sets of moral foundations. Journal of Personality and Social Psychology, 96(5), 1029-1046. https://doi.org/10. 1037/a0015141.

Graham, J., Nosek, B. A., Haidt, J., Iyer, R., Koleva, S., \& Ditto, P. H. (2011). Mapping the moral domain. Journal of Personality and Social Psychology, 101(2), 366-385. https://doi.org/10.1037/ a0021847.

Greene, J. D. (2007). Why are VMPFC patients more utilitarian? A dual-process theory of moral judgment explains. Trends in Cognitive Sciences, 11(8), 322-323. https://doi.org/10.1016/j.tics. 2007.06.004.

Greene, J. D. (2015). The cognitive neuroscience of moral judgment and decision making. The Moral Brain: A Multidisciplinary Perspective. https://doi.org/10.7551/mitpress/9988.003.0017.

Gromet, D. M., Kunreuther, H., \& Larrick, R. P. (2013). Political ideology affects energy-efficiency attitudes and choices. Proceedings of the National Academy of Sciences of the United States of America, 110(23), 9314-9319. https://doi.org/10.1073/pnas.1218453110.

Grünhage, T., \& Reuter, M. (2020). Personality's influence on political orientation extends to concrete stances of political controversy in germany - cross-nationally and consistently. Journal of Social and Political Psychology, accepted. https://doi.org/10.5964/jspp.v8i2.1133.

Guglielmo, S. (2018). Unfounded dumbfounding: How harm and purity undermine evidence for moral dumbfounding. Cognition, 170, 334-337. https://doi.org/10.1016/j.cognition.2017.08.002.

Haidt, J. (2001). The emotional dog and its rational tail: A social intuitionist approach to moral judgment. Psychological Review, 108(4), 814-834. https://doi.org/10.1037/0033-295X.108.4.814.

Haidt, J. (2007). The new synthesis in moral psychology. Science, 316(5827), 998-1002. https://doi.org/ $10.1126 /$ science. 1137651 .

Haidt, J., Bjorklund, F., \& Murphy, S. (2000). Moral dumbfounding: When intuition finds no reason. University of Virginia Working Paper. In University of Virginia. 
Haidt, J., \& Graham, J. (2007). When morality opposes justice: Conservatives have moral intuitions that liberals may not recognize. Social Justice Research, 20(1), 98-116. https://doi.org/10.1007/s11211007-0034-z.

Haidt, J., Graham, J., \& Joseph, C. (2009). Above and Below Left-Right: Ideological narratives and moral foundations. Psychological Inquiry, 20(2-3), 110-119. https://doi.org/10.1080/ 10478400903028573.

Haidt, J., \& Joseph, C. (2004). Intuitive ethics: how innately prepared intuitions generate culturally variable virtues. Daedalus, 133(4), 55-66.

Haidt, J., \& Joseph, C. (2011). How moral foundations theory succeeded in building on sand: A response to suhler and churchland. Journal of Cognitive Neuroscience, 23(9), 2117-2122. https://doi.org/10. 1162/jocn.2011.21638.

Hamilton, M. (2006). Eating death vegetarians, meat and violence. Food, Culture \& Society, 9(2), 155-177. https://doi.org/10.2752/155280106778606053.

Harper, C. A., \& Harris, A. J. (2017). Applying moral foundations theory to understanding public views of sexual offending. Journal of Sexual Aggression, 23(2), 111-123. https://doi.org/10.1080/ 13552600.2016.1217086.

Havlicek, J., \& Lenochova, P. (2006). The effect of meat consumption on body odor attractiveness. Chemical Senses, 31(8), 747-752. https://doi.org/10.1093/chemse/bj1017.

Hayes, A. F. (2017). Introduction to mediation, moderation and conditional process analysis (2nd ed.). New York: Guilford Press.

Hodson, G., \& Earle, M. (2018). Conservatism predicts lapses from vegetarian/vegan diets to meat consumption (through lower social justice concerns and social support). Appetite, 120, 75-81. https://doi.org/10.1016/j.appet.2017.08.027.

Hoek, A. C., Luning, P. A., Stafleu, A., \& De Graaf, C. (2004). Food-related lifestyle and health attitudes of Dutch vegetarians, non-vegetarian consumers of meat substitutes, and meat consumers. Appetite, 42(3), 265-272. https://doi.org/10.1016/j.appet.2003.12.003.

Hyers, L. L. (2006). Myths used to legitimize the exploitation of animals: An application of social dominance theory. Anthrozoos, 19(3), 194-210. https://doi.org/10.2752/089279306785415538.

Infratest dimap. (2015). Die Positionierung der politischen Parteien im Links-Rechts-Kontinuum. Retrieved May 5, 2018, from http://www.infratest-dimap.de/ulpoads/media/LinksRechts_Nov2015_ 01.pdf

Iurino, K., \& Saucier, G. (2020). Testing measurement invariance of the moral foundations questionnaire across 27 Countries. Assessment, 27(2), 365-372. https://doi.org/10.1177/1073191118817916.

Iyer, R., Koleva, S., Graham, J., Ditto, P., \& Haidt, J. (2012). Understanding libertarian morality: The psychological dispositions of self-identified libertarians. PLOS ONE, 7(8), 42366. https://doi.org/10. 1371/journal.pone.0042366.

Jockel, S., Dogruel, L., Arendt, K., Stahl, H., \& Bowman, N. (2010). Moral Foundations Questionnaire (German Translation). Retrieved May 12, 2020, from https://moralfoundations.org/questionnaires/

Jost, J. T., Glaser, J., Kruglanski, A. W., \& Sulloway, F. J. (2003). Political conservatism as motivated social cognition. Psychological Bulletin, 129(3), 339-375. https://doi.org/10.1037/0033-2909.129.3. 339.

Kalof, L., Dietz, T., Stern, P. C., \& Guagnano, G. A. (1999). Social Psychological and structural influences on vegetarian beliefs. Rural Sociology, 64(3), 500-511. https://doi.org/10.1111/j.15490831.1999.tb00364.x.

Kidwell, B., Farmer, A., \& Hardesty, D. M. (2013). Getting liberals and conservatives to go green: Political ideology and congruent appeals. Journal of Consumer Research, 40(2), 350-367. https:// doi.org/10.1086/670610.

Koleva, S. P., Graham, J., Iyer, R., Ditto, P. H., \& Haidt, J. (2012). Tracing the threads: How five moral concerns (especially Purity) help explain culture war attitudes. Journal of Research in Personality, 46(2), 184-194. https://doi.org/10.1016/j.jrp.2012.01.006.

Kugler, M., Jost, J. T., \& Noorbaloochi, S. (2014). Another Look at moral foundations theory: Do authoritarianism and social dominance orientation explain liberal-conservative differences in "moral" intuitions? Social Justice Research, 27(4), 413-431. https://doi.org/10.1007/s11211-0140223-5.

Low, M., \& Wui, M. G. L. (2016). Moral foundations and attitudes towards the poor. Current Psychology, 35(4), 650-656. https://doi.org/10.1007/s12144-015-9333-y.

Markett, S. (2016). Vegetarismus und Persönlichkeit. unpublished. 
McCright, A. M., \& Dunlap, R. E. (2011). The politicization of climate change and polarization in the American public's views of global warming, 2001-2010. Sociological Quarterly, 52(2), 155-194. https://doi.org/10.1111/j.1533-8525.2011.01198.x.

McHugh, C., McGann, M., Igou, E. R., \& Kinsella, E. L. (2017). Searching for moral dumbfounding: Identifying measurable indicators of moral dumbfounding. Collabra Psychology. https://doi.org/10. 1525/collabra.79.

McMichael, A. J., Powles, J. W., Butler, C. D., \& Uauy, R. (2007). Food, livestock production, energy, climate change, and health. Lancet, 370(9594), 1253-1263. https://doi.org/10.1016/S01406736(07)61256-2.

Nilsson, A., Erlandsson, A., \& Västfjäll, D. (2016). The congruency between moral foundations and intentions to donate, self-reported donations, and actual donations to charity. Journal of Research in Personality, 65, 22-29. https://doi.org/10.1016/j.jrp.2016.07.001.

Peterson, B. E., Doty, R. M., \& Winter, D. G. (1993). Authoritarianism and attitudes toward contemporary social issues. Personality and Social Psychology Bulletin, 19(2), 174-184. https://doi. org/10.1177/0146167293192006.

Pfeiler, T. M., \& Egloff, B. (2018). Examining the "Veggie" personality: Results from a representative German sample. Appetite, 120, 246-255. https://doi.org/10.1016/j.appet.2017.09.005.

Pratto, F., Sidanius, J., Stallworth, L. M., \& Malle, B. F. (1994). Social dominance orientation: A personality variable predicting social and political attitudes. Journal of Personality and Social Psychology, 67(4), 741-763. https://doi.org/10.1037/0022-3514.67.4.741.

Rothgerber, H. (2013). Real men don't eat (vegetable) quiche: Masculinity and the justification of meat consumption. Psychology of Men and Masculinity, 14(4), 363-375. https://doi.org/10.1037/ a0030379.

Royzman, E. B., Kim, K., \& Leeman, R. F. (2015). The curious tale of Julie and Mark: Unraveling the moral dumbfounding effect. Judgment and Decision Making, 10(4), 296-313.

Rozin, P., Hormes, J. M., Faith, M. S., \& Wansink, B. (2012). Is meat male? A quantitative multimethod framework to establish metaphoric relationships. Journal of Consumer Research, 39(3), 629-643. https://doi.org/10.1086/664970.

Ruby, M. B. (2012). Vegetarianism. A blossoming field of study. Appetite, 58(1), 141-150. https://doi.org/ 10.1016/j.appet.2011.09.019.

Ruby, M. B., \& Heine, S. J. (2011). Meat, morals, and masculinity. Appetite, 56(2), 447-450. https://doi. org/10.1016/j.appet.2011.01.018.

Schein, C., \& Gray, K. (2015). The unifying moral dyad: liberals and conservatives share the same harmbased moral template. Personality and Social Psychology Bulletin. https://doi.org/10.1177/ 0146167215591501.

Silver, J. R., \& Silver, E. (2017). Why are conservatives more punitive than liberals? A moral foundations approach. Law and Human Behavior, 41(3), 258-272. https://doi.org/10.1037/lhb0000232.

Simpson, A. (2017). Moral Foundations Theory. In Encyclopedia of Personality and Individual Differences (pp. 1-11). https://doi.org/10.1007/978-3-319-28099-8_1253-1

Spencer, C. (1996). The Heretic's Feast: A History of Vegetarianism. https://doi.org/10.2307/2171268.

Suhler, C. L., \& Churchland, P. (2011). Can innate, modular "foundations" explain morality? challenges for haidt's moral foundations theory. Journal of Cognitive Neuroscience, 23(9), 2103-2116. https:// doi.org/10.1162/jocn.2011.21637.

Thomson, J. J. (1985). The trolley problem. The Yale Law Journal, 94(6), 1395-1415.

Vaughan, T. J., Bell Holleran, L., \& Silver, J. R. (2019). Applying moral foundations theory to the explanation of capital jurors' sentencing decisions. Justice Quarterly, 36(7), 1176-1205. https://doi. org/10.1080/07418825.2018.1537400.

White, R. F., Seymour, J., \& Frank, E. (1999). Vegetarianism among US women physicians. Journal of the Academy of Nutrition and Dietetics, 99(5), 595-598.

Wolsko, C., Ariceaga, H., \& Seiden, J. (2016). Red, white, and blue enough to be green: Effects of moral framing on climate change attitudes and conservation behaviors. Journal of Experimental Social Psychology, 65, 7-19. https://doi.org/10.1016/j.jesp.2016.02.005. 
Yilmaz, O., \& Saribay, S. A. (2017). Activating analytic thinking enhances the value given to individualizing moral foundations. Cognition, 165, 88-96. https://doi.org/10.1016/j.cognition.2017. 05.009 .

Zajonc, R. B. (1980). Feeling and thinking: Preferences need no inferences. American Psychologist, 35(2), 151-175. https://doi.org/10.1037/0003-066X.35.2.151.

Publisher's Note Springer Nature remains neutral with regard to jurisdictional claims in published maps and institutional affiliations.

\section{Authors and Affiliations}

\section{Thomas Grünhage ${ }^{1}$ (D) $\cdot$ Martin Reuter ${ }^{1,2,3}$}

Thomas Grünhage

thomas.gruenhage@uni-bonn-diff.de

1 Department of Psychology, University of Bonn, Kaiser-Karl-Ring 9, 53111 Bonn, Germany

2 Laboratory of Neurogenetics, University of Bonn, Kaiser-Karl-Ring 9, 53111 Bonn, Germany

3 Center for Economics and Neuroscience (CENs), University of Bonn, Nachtigallenweg 86, 53127 Bonn, Germany 